\title{
Modeling Hysteresis with Inertial-Dependent Prandtl-Ishlinskii Model in Wide-Band Frequency-Operated Piezoelectric Actuator
}

\author{
Vahid Hassani, Tegoeh Tjahjowidodo, and Albert D. Soetarto \\ Division of Mechatronics \& Design, School of Mechanical and Aerospace Engineering, Nanyang Technological University, \\ 50 Nanyang Avenue, Singapore 639798 \\ Correspondence should be addressed to Vahid Hassani, h_vhd@yahoo.com
}

Received 12 November 2011; Accepted 3 January 2012

Academic Editor: Tao Li

Copyright ( 2012 Vahid Hassani et al. This is an open access article distributed under the Creative Commons Attribution License, which permits unrestricted use, distribution, and reproduction in any medium, provided the original work is properly cited.

One of the major problems occurring in many technical applications is the presence of the hysteretic behavior in sensors and actuators, which causes a nonlinear relationship between input and output variables in such devices. Since the nonlinear phenomenon of hysteresis degrades the performance of the piezoelectric materials and piezoelectric drive mechanisms, for example, in positioning control framework, it has to be characterized in order to mitigate the effect of the nonlinearity in the devices. This paper is aimed to characterize and model the hysteresis in typical piezoelectric actuators under load-free and preloaded circumstances incorporating the inertial effect of the system. For this purpose, the piezoelectric actuator is modeled as a mass-spring-damper system, which is expressed in terms of a stop operator as one of the essential yet efficient hysteresis operators in the Prandtl-Ishlinskii (PI) model. The reason of utilizing the stop operator in this study is for the sake of control purposes, as the stop operator plays as the inverse of the play operator in the PI model and can be used in a feed-forward controller scheme to suppress the effect of hysteresis in general control framework. The results reveal that this model exhibits better correspondence to the measurement output compared to that of the classical PI model.

\section{Introduction}

Hysteresis is a nonlinear phenomenon that occurs in some types of materials such as piezoceramics, shape-memory alloys, and magnetostrictive actuators. The word "hysteresis" refers to systems that have memory such that similar loops are repeated in each cycle of operation in every dynamical system and, after removal of the force or electrical field, the system does not return to its original location. In this phenomenon, the current output depends also on the history of the input.

The effect of hysteresis nonlinearity can be neglected in some systems. In contrast, ignoring this phenomenon in other types of systems that possess severe hysteresis might create undesirable consequences such as inaccuracy in open loop system, limit cycle, degradation of the tracking performance, and even instability of closed loop system.

To overcome this challenge, some mathematical models, for example, the Preisach model and the PI model, have been proposed to capture the effect of hysteresis in any mechanical systems. Utilization of the PI model is addressed in many works to characterize the hysteresis due to its simplicity compared to the Preisach model. Wang et al. [1] utilized the classical PI model and neural network approximator to design a robust adaptive control, which ensures that the tracking error is bounded in the presence of unknown hysteresis in a closed-loop system. The generalized PI is proposed for modeling an asymmetric hysteresis in piezoceramic actuators, where a linear function is defined to modify the threshold of the play operator of the model [2]. Krejci and Kuhnen [3] presented a new method of constructing the inverse of the hysteresis model in an analytical form for the system with hysteresis and creep and used the proposed model in a feed-forward controller to mitigate the nonlinearity arisen from the hysteresis. Al Janaideh et al. [4] presented a method to construct the inverse of the generalized PI model to be used in a feed-forward loop cascaded with an adaptive controller to reduce the effect of hysteresis in a piezoelectric actuator, and in another paper, they utilized the generalized PI model to design a robust 


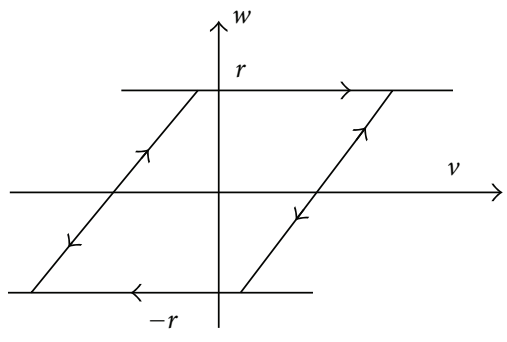

Figure 1: Classical stop operator.

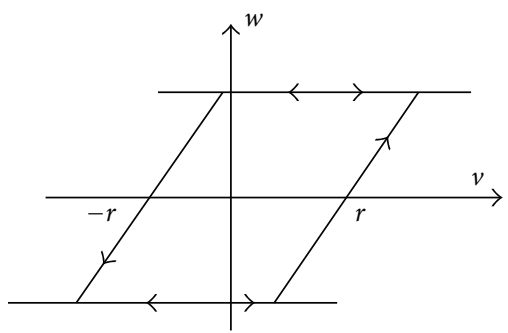

FIGURE 2: Classical play operator.

sliding mode controller to ensure the system stability for smart actuators [5]. A new strategy is introduced by Chen [6] to fuse the PI model with adaptive control techniques, which enhances the global stability of the system.

Various rate-dependent PI models have been proposed to capture the hysteresis in different rate of input or different frequency values of input applied to the piezoelectric actuators. Al Janaideh et al. [7] proposed a new rate-dependent PI model, which utilized logarithmic threshold value and density function in the play operator to characterize the hysteresis of a piezoelectric actuator under dynamically varying input up to $200 \mathrm{~Hz}$. In the paper, they also characterized the hysteresis of a piezoelectric actuator up to $500 \mathrm{~Hz}$ and showed that the hysteresis loop gets larger at higher frequencies as well as it generates lower displacement as the frequency is increasing [8]. Kuhnen and Janocha [9] developed a modified PI model to characterize the complex hysteresis in actuators and sensors and presented the inverse of this model in an analytical form. Ang et al. [10] proposed the hysteresis model at low frequencies up to $50 \mathrm{~Hz}$ and utilized a linear function relating the slope of the hysteresis loop to input rate applied to the actuator. Subsequently, an advanced model was proposed to characterize the nonlinearity in a piezoelectric actuator under ill-conditioned hysteresis [11]. An adaptive controller was designed to capture the nonlinear effects of the giant magnetostrictive actuator using the PI model to compensate for the hysteresis which was reported by Wang et al. [12] Goldfarb and Celanovic [13] proposed a rate-independent generalized Maxwell-Slip model for force and positioning control of microrobotic systems. Quant et al. [14] proposed a nonlinear Maxwell-Slip-based model to replace the linear constitutive equations of piezoelectric actuators to

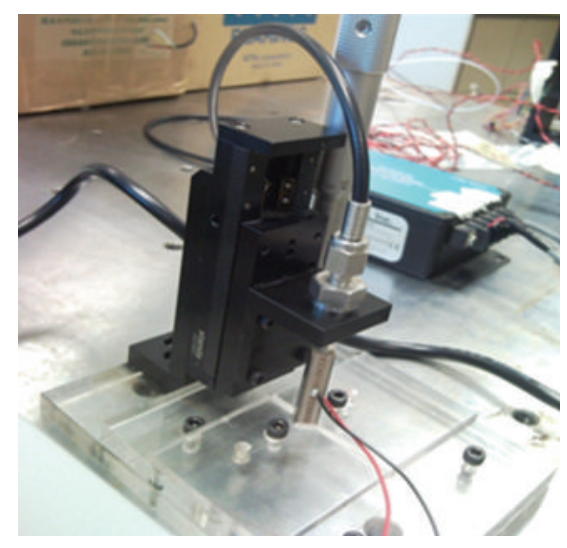

FIGURE 3: Configuration of the experimental setup.

make a comparison between two models. A Maxwell-Slipbased model was proposed to capture the hysteresis in piezoelectric actuator, and the parameters of this model were identified by the linear programming method [15]. Three fitness functions were proposed in terms of the BoucWen model including mass-spring-damper characteristics of piezoelectric actuator, and these functions were minimized using the genetic algorithm method [16]. In other study, piezoelectric actuator was employed as Impact Drive Mechanism, and its model was constructed assuming the system as a spring-mass-damper system, where nonlinearity was modeled using the Bouc-Wen model, and finally the parameters of this system were identified by an adaptive method [17].

In this study, an inertial-dependent model is proposed to overcome the large amount of errors imposed in the modeling with the classical PI model, in particular in capturing the hysteresis at high frequencies as well as high amplitudes of inputs applied to a piezoelectric actuator under load-free and preloaded conditions. As a rate-independent model, it is able to capture the hysteresis at different input magnitudes and frequencies even in the presence of preloading force.

\section{Classical Prandtl-Ishlinskii (PI) Model}

One of the well-known operator-based models, which are used to characterize the hysteresis in piezoceramics and other types of materials, is the classical PI model that utilizes two essential hysteresis operators, namely, the play operator and the stop operator.

2.1. Stop Operator. The rate-independent stop operator is illustrated in Figure 1. Conceptually, this operator determines the linear stress-strain $(w-v)$ relationship as in the Hook's law, when the stress is less than the yield stress, $r$ [7]. In analytical form, assume that $C_{m}\left[0, t_{E}\right]$ is the space of piecewise monotone continuous functions, a function $e_{r}$ : $R \rightarrow R$ is defined by

$$
e_{r}(v)=\min (r, \max (-r, v))
$$




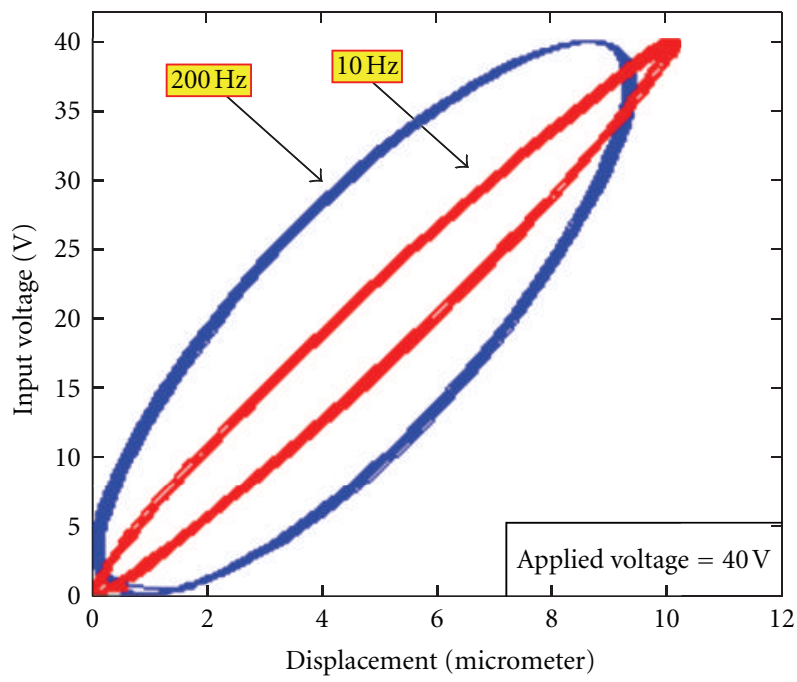

(a)

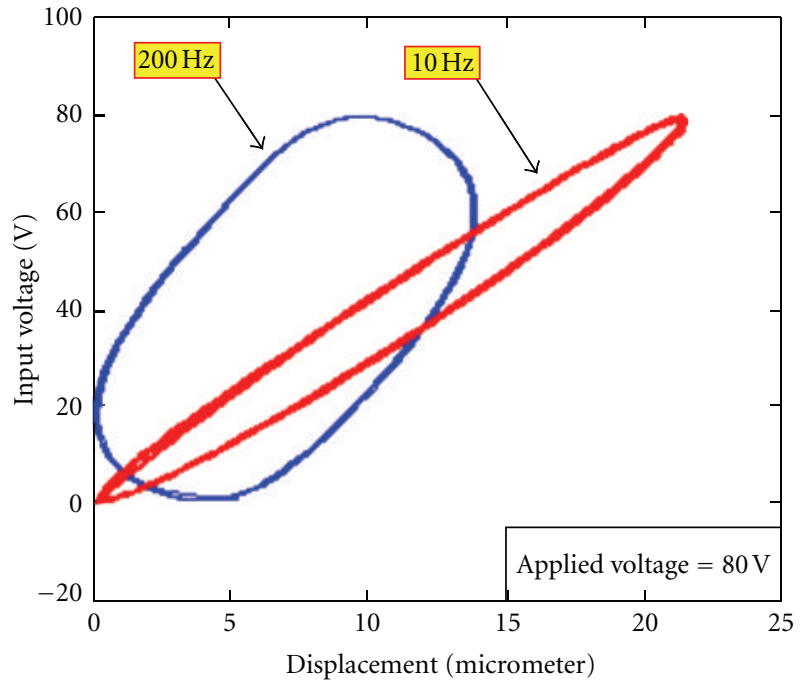

(b)

FIgURE 4: Width and slope of the hysteresis curve at different frequencies and input amplitudes for load-free piezoelectric actuator.

with $r \geq 0$. For any input $v(t) \in C_{m}\left[0, t_{E}\right]$ and any initial value $\omega_{-1} \in R$, the stop operator $E_{r}$ can be expressed by the following definition:

$$
\begin{aligned}
E_{r}\left[v ; \omega_{-1}\right](0) & =e_{r}\left(v(0)-\omega_{-1}\right), \\
E_{r}\left[v ; \omega_{-1}\right](t) & =e_{r}\left(v(t)-v\left(t_{i}\right)+E_{r}\left[v ; \omega_{-1}\right]\left(t_{i}\right)\right), \\
& \text { for } t_{i}<t \leq t_{i+1}, \quad 0<i \leq N-1,
\end{aligned}
$$

where $0=t_{0}<t_{1}<\cdots<t_{N}=t_{E}$ is a part of $\left[0, t_{E}\right]$, such that the function $v$ is monotone on each of the subintervals $\left[t_{i}, t_{i+1}\right]$.

2.2. Play Operator. The rate-independent play operator is illustrated in Figure 2. This operator implies the reciprocating motion of a piston inside a cylinder with length $2 r$, where the instantaneous position of center of piston is defined by $v$ and $\omega$ as input and output subsequently [7]. In analytical form, for any input $v(t) \in C_{m}\left[0, t_{E}\right]$ and $r \geq 0$, the play operator is inductively defined by

$$
\begin{aligned}
F_{r}\left[v ; \omega_{-1}\right](0) & =f_{r}\left(v(0)-\omega_{-1}\right), \\
F_{r}\left[v ; \omega_{-1}\right](t) & =f_{r}\left(v(t), F_{r}\left[v ; \omega_{-1}\right]\left(t_{i}\right)\right), \\
\text { for } t_{i}<t & \leq t_{i+1}, \quad 0<i \leq N-1,
\end{aligned}
$$

where

$$
f_{r}(v, \omega)=\max (v-r, \min (v, \omega))
$$

$\omega_{-1}$ defines the initial state at time $t=0$.

\section{Inertial-Dependent Prandtl-Ishlinskii (PI) Model}

In order to determine the dynamic characteristics of the piezoelectric actuators, the linear constitutive equation has been proposed [18]. A piezoelectric element can be represented by an element with electrical and mechanical gates in linear form, which is expressed mathematically in (5) disregarding the presence of any nonlinear effects

$$
T=C^{E} S-e E .
$$

Since this equation is not involved in the nonlinear phenomenon of hysteresis, it is required to model the nonlinear characteristics of the piezoelectric actuator. For practical applications, engineering variables such as force, speed, electrical current, and voltage are required. In order to simplify the analysis, the strain, $S$, stress, $T$, and electrical field, $E$ in (5) are substituted by measurable counterparts, namely, the displacement, $x$, force, $F$, and voltage, $U$, as shown in

$$
F=A \cdot U+Z x
$$

Consequently, the constitutive equation can be transformed into the Laplace domain as presented in (7), where $Z$ represents the mechanical impedance, $m$ is the equivalent mass of the piezoceramic, $c$ is the damping factor, and $k$ is the stiffness of the piezoelectric actuator

$$
Z=m s^{2}+c s+k
$$

Intuitively, in this model, the piezoelectric actuator is assumed as a mass-spring-damper system. Based on this assumption, basic equation of motion for such systems can be written incorporating with the PI model to take into account the both linear and nonlinear characteristics of the piezoelectric actuator. As a result, the following relationships are proposed in terms of two essential operators of the PI model, namely, the play operator:

$$
X=\alpha \cdot V+\beta \cdot F_{P \cdot L}-m_{e q} \frac{d^{2} f_{P \cdot O}(V)}{d t^{2}}-c_{e q} \frac{d f_{P \cdot O}(V)}{d t},
$$




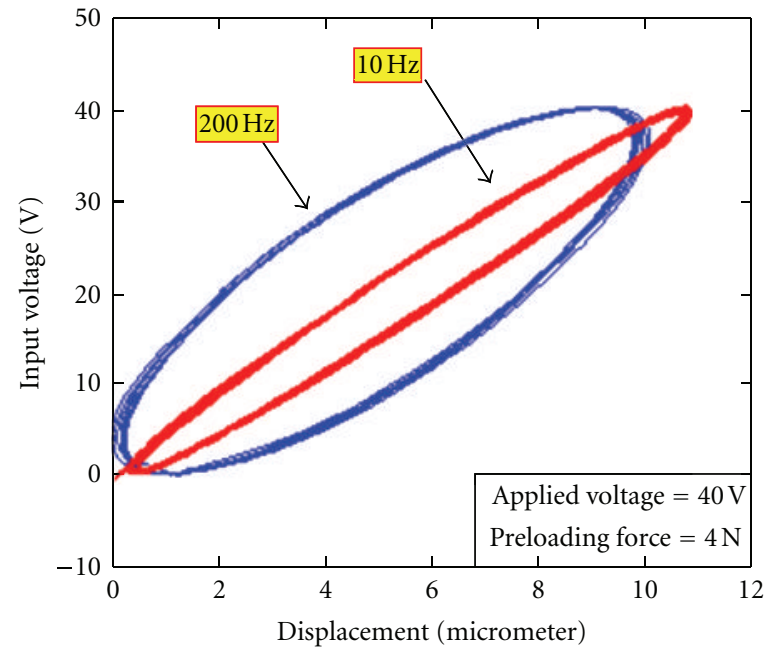

(a)

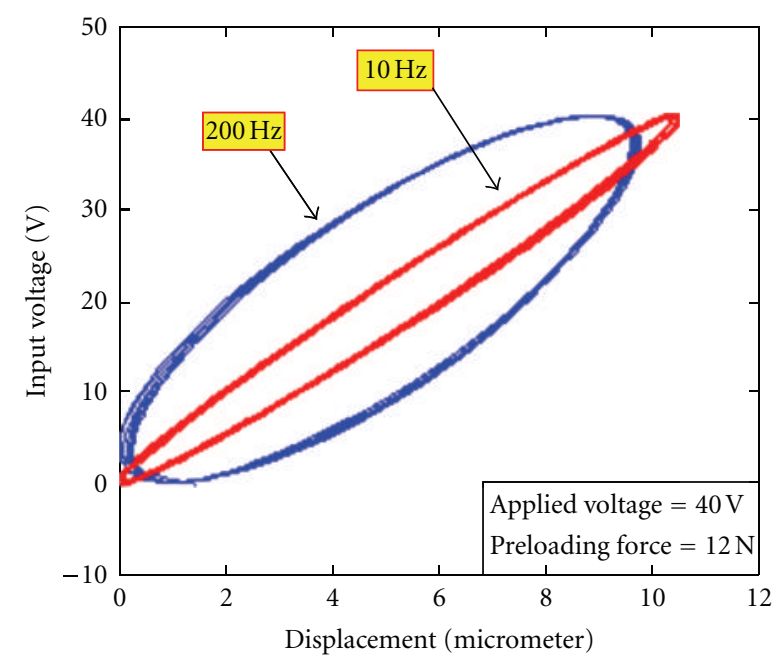

(c)

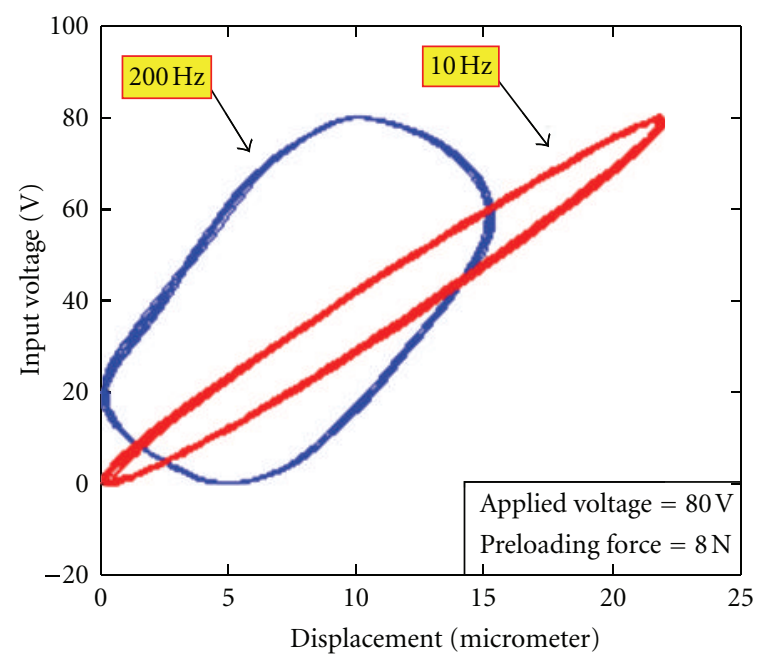

(e)

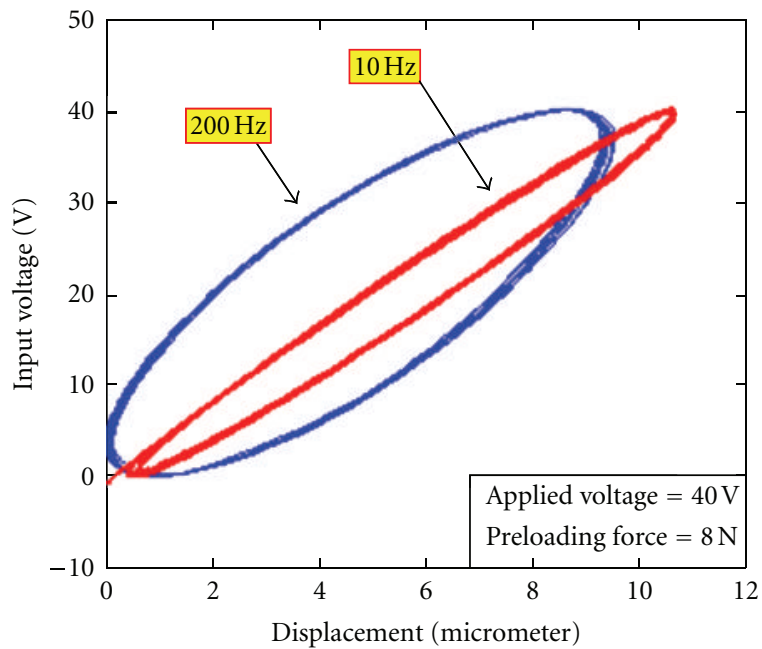

(b)

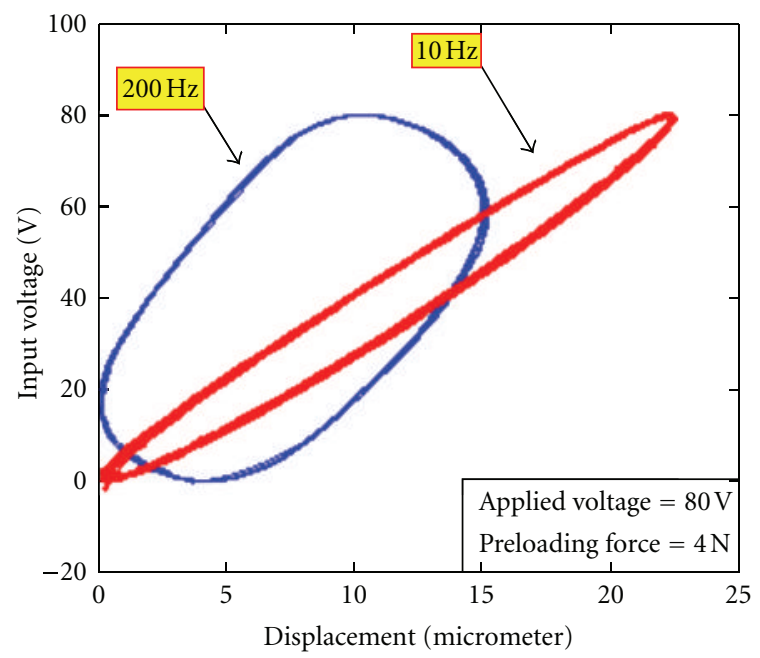

(d)

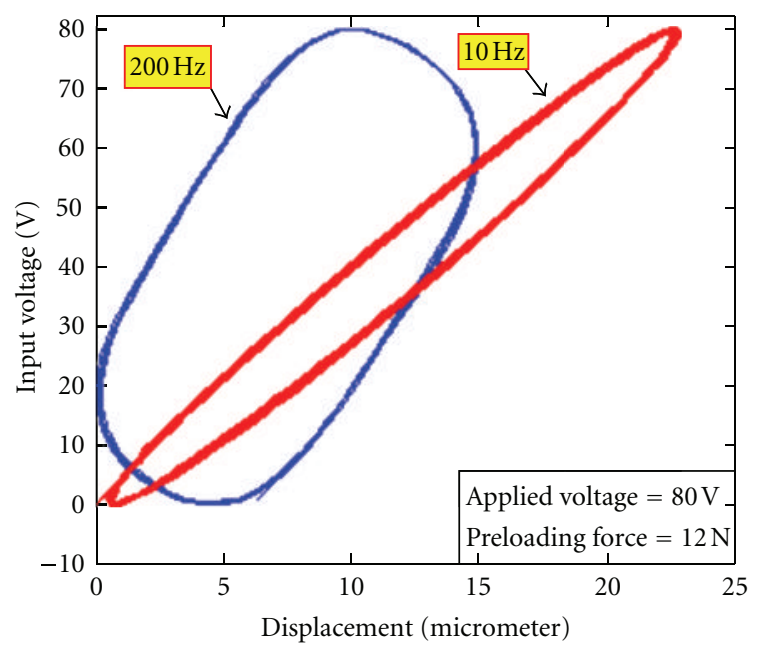

(f)

FIGURE 5: Width and slope of the hysteresis curve at different frequencies and input amplitudes for preloaded piezoelectric actuator. 


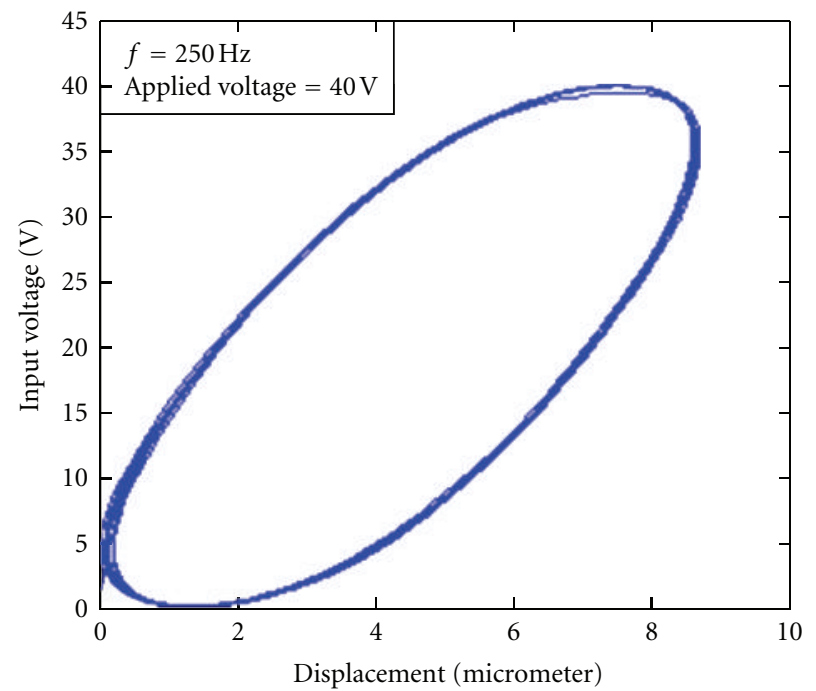

(a)

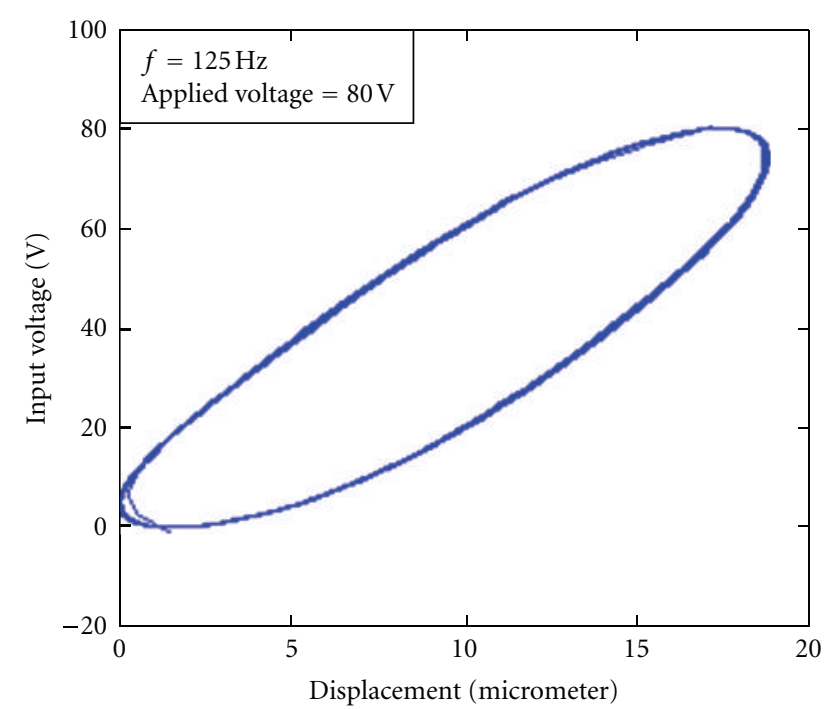

(b)

Figure 6: Asymmetric hysteresis curve at different frequencies and input amplitudes for load-free piezoelectric actuator.

and inversely in the stop operator, it can be expressed as

$$
f_{S \cdot O}(X)=\beta \cdot F_{P \cdot L}-m_{e q} \frac{d^{2} X}{d t^{2}}-c_{e q} \frac{d X}{d t}-k_{e q} X
$$

where $m_{e q}, c_{e q}$, and $k_{e q}$ are the equivalent mass, damping, and stiffness factors, respectively. $F_{P \cdot L}$ stands for the preloading force when the piezoelectric actuator is exposed to the preloading condition, which in turn involves two terms of external force and stiffness of the preloading devices which are expressed by $F_{P \cdot L}=F_{\text {ext }}+K_{\text {eq, ext }} \cdot x$. In (8) and (9), $V$ represents the input voltage applied to the piezoelectric actuator as the input of the play operator and $X$ represents the desired displacement of the actuator as the input of the stop operator. $\alpha$ and $\beta$ stand as correction coefficients of the input voltage in the play operator and the preloading force $F_{P \cdot L}$, respectively. $f_{S \cdot O}(X)$ and $f_{P \cdot O}(V)$ are subsequently the output of the stop operator and the play operator.

This model takes into consideration two important terms of inertial and damping effects which are shown by $m_{e q} \ddot{X}$ and $c_{e q} \dot{X}$. In the sense of frequency response, these two terms are expressed by $m_{e q} \omega^{2} X$ and $c_{e q} \omega X$. As a result, these terms are function of frequency, and they vary with variations of the input frequency. Due to this characteristic, the modeling of the hysteresis in piezoelectric actuators is expected to perform better compared to that with the classical PI model.

\section{Experimental Set Up}

A dedicated set up was built to characterize a piezoelectric actuator experimentally. In this work, the piezoceramic actuator (P-887.90, from PHYSIK Instrument Co.) was used. This actuator provides maximum displacement of $36 \pm$ $10 \% \mu \mathrm{m}$ at maximum applied voltage of $120 \mathrm{~V}$. The PZT actuator is driven using a power amplifier (E.663, PHYSIK Instrument Co.), which multiplies any input voltage by gain 10 and sends it to the piezoelectric actuator. A capacitive sensor (CS1, Micro-Epsilon Co. with resolution of $0.75 \mathrm{~nm}$ and operating temperature range of $-50^{\circ} \mathrm{C}$ to $200^{\circ} \mathrm{C}$ ) was utilized to measure the displacement of PZT actuator in terms of voltage (see Figure 3 ).

\section{Experimental Results}

In order to characterize the hysteretic behavior of the piezoelectric actuator, two sets of sinusoidal inputs for lowamplitude voltage signal (20 V amplitude with $20 \mathrm{~V}$ bias) and high-amplitude voltage signal (40 V amplitude with $40 \mathrm{~V}$ bias) were applied to the piezoelectric actuator in loadfree and preloading conditions. These sets of input signals were applied at varying frequency ranging from $10 \mathrm{~Hz}$ to $200 \mathrm{~Hz}$ and different preloading forces of $4 \mathrm{~N}, 8 \mathrm{~N}$, and $12 \mathrm{~N}$. The reason of selecting different amplitudes besides different frequencies is to analyze the hysteresis characteristic in the piezoelectric actuator in terms of amplitude and frequency variations. Different preload condition on the piezoelectric actuator is also expected to affect the hysteresis characteristics. This motivates the experiment to be conducted at different preloading forces.

Applying two sets of low-amplitude and high-amplitude inputs at different frequencies besides different values of preloading force implies three important aspects in the hysteretic behavior. The first thing, which is observed from this experiment, is attributed to the rate dependency of the hysteresis curve; that is, when the rate of the input voltage is increased, the width of the hysteresis curve is also increasing. Figure 4 shows that the maximum width of the hysteresis at frequency of $200 \mathrm{~Hz}$ with low input voltage has become 3.57 times as that of the hysteresis curve at frequency of $10 \mathrm{~Hz}$ with the same amount of voltage amplitude. For high amplitude voltage, the width of the hysteresis curve at frequency of $200 \mathrm{~Hz}$ has grown up to 4.3 times higher than that of the hysteresis width at frequency of $10 \mathrm{~Hz}$. The 

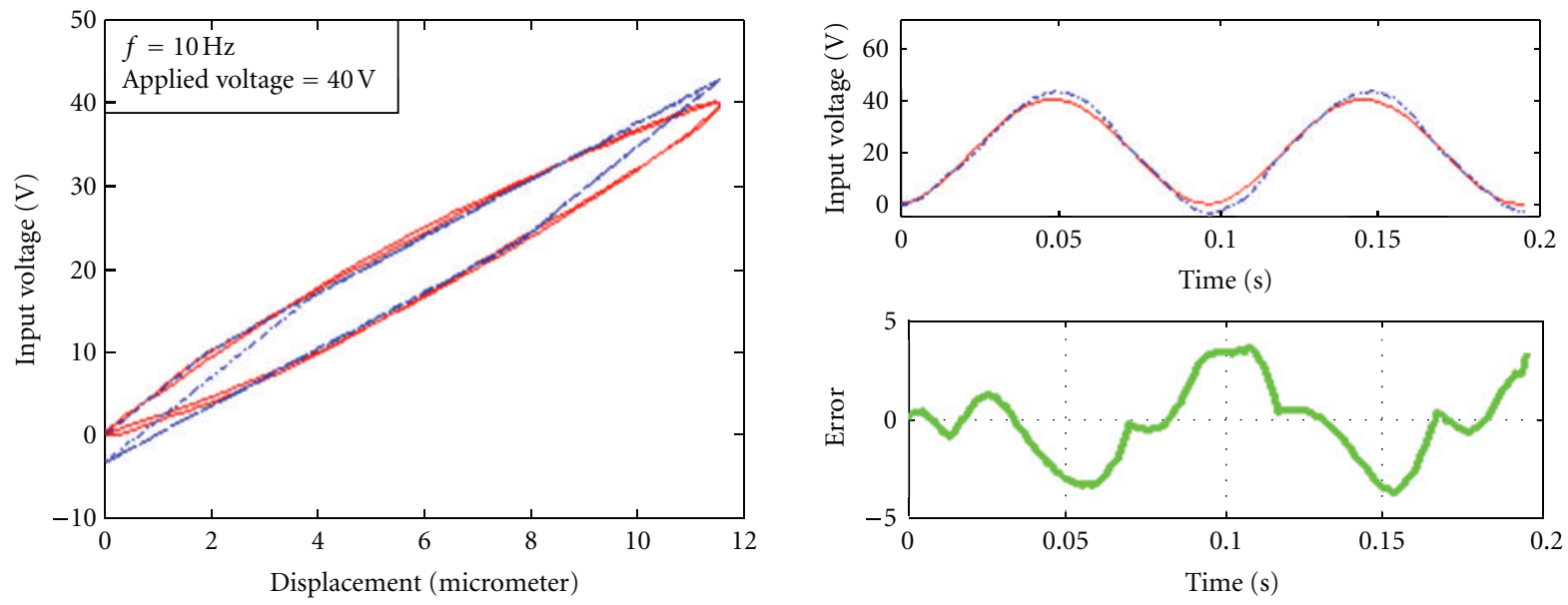

(a)
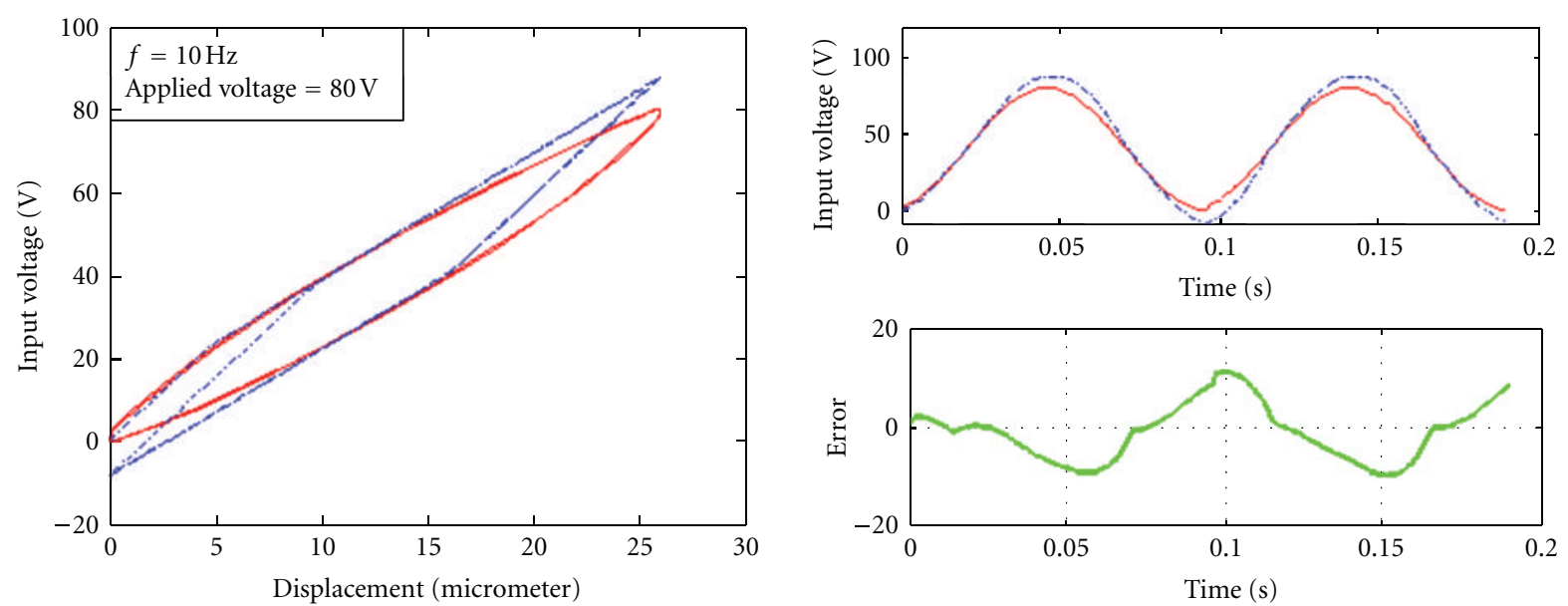

(b)
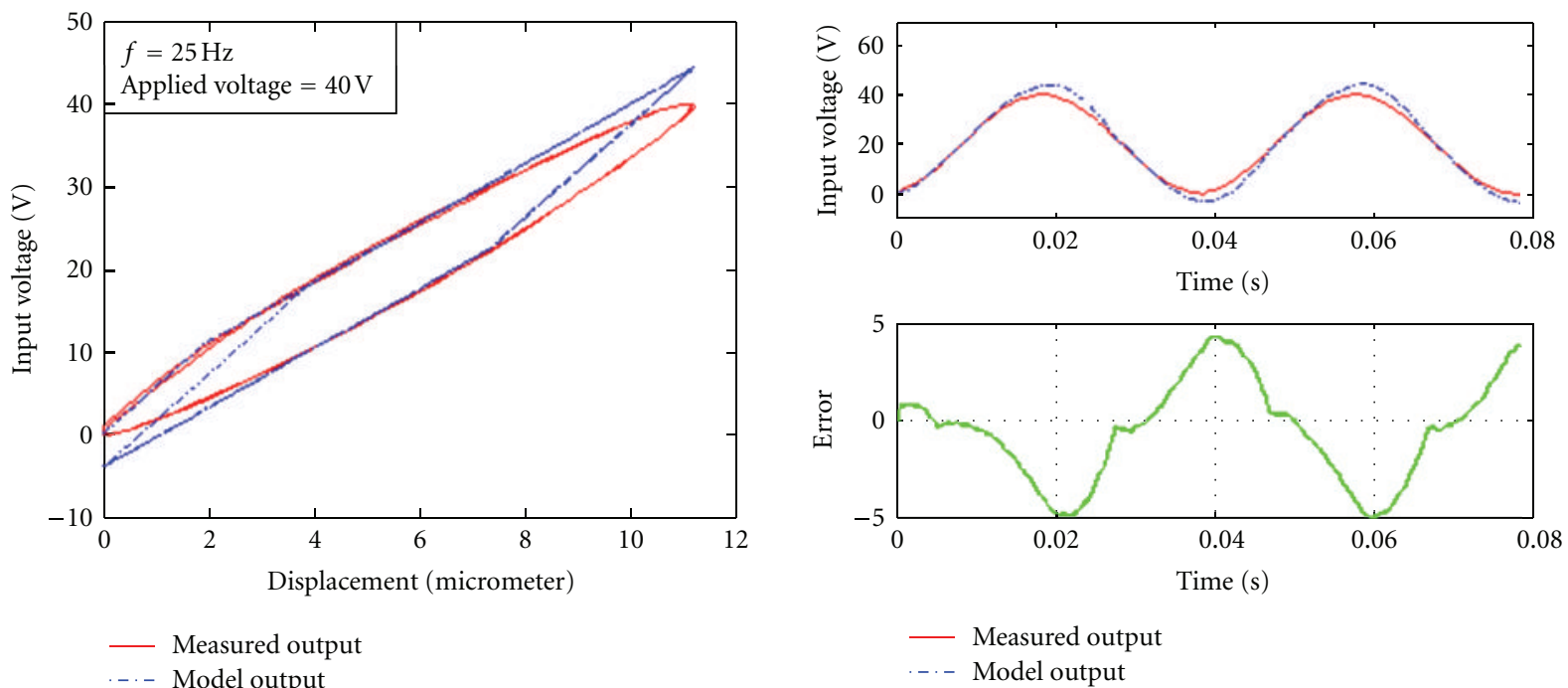

(c)

Figure 7: Continued. 

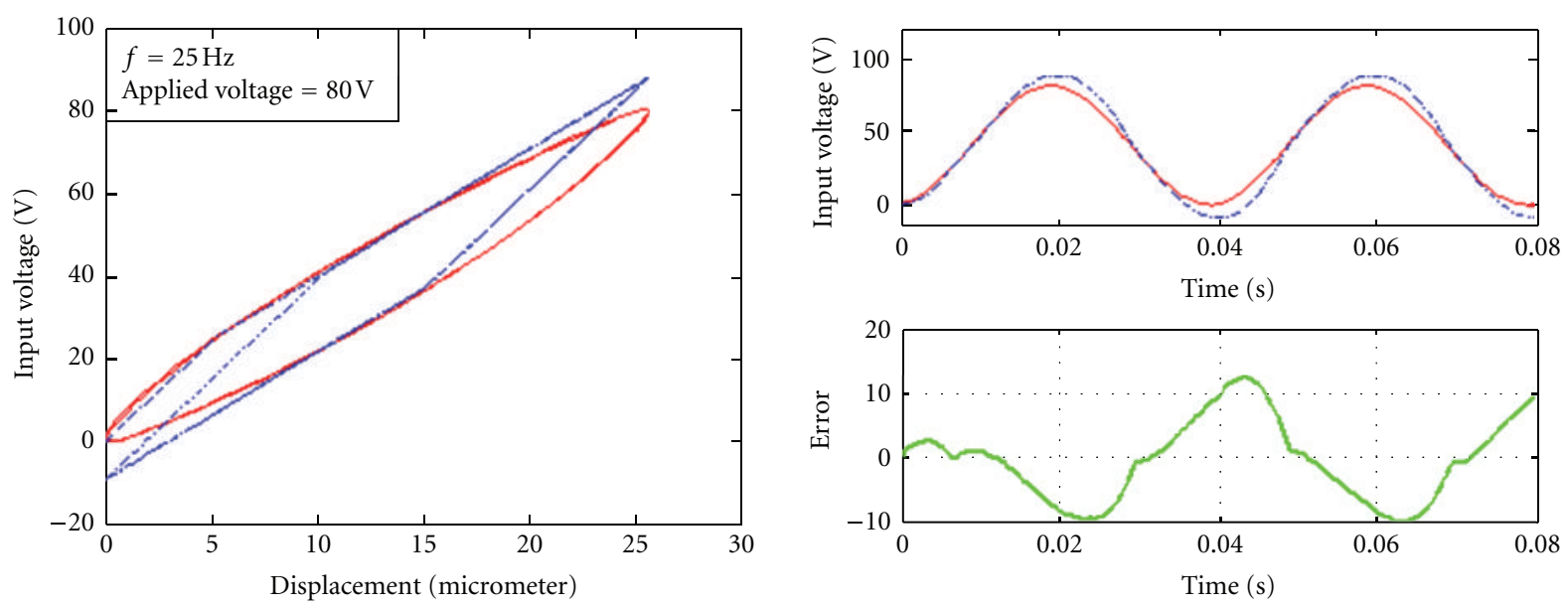

(d)
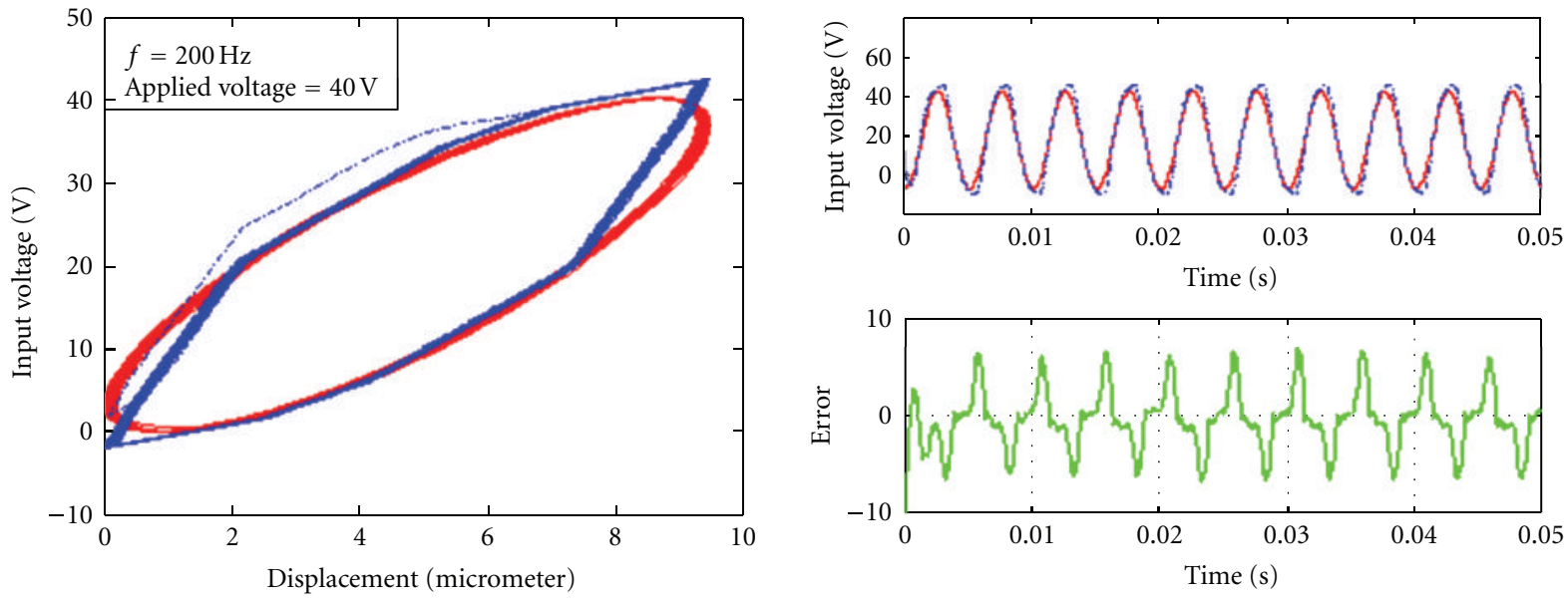

(e)
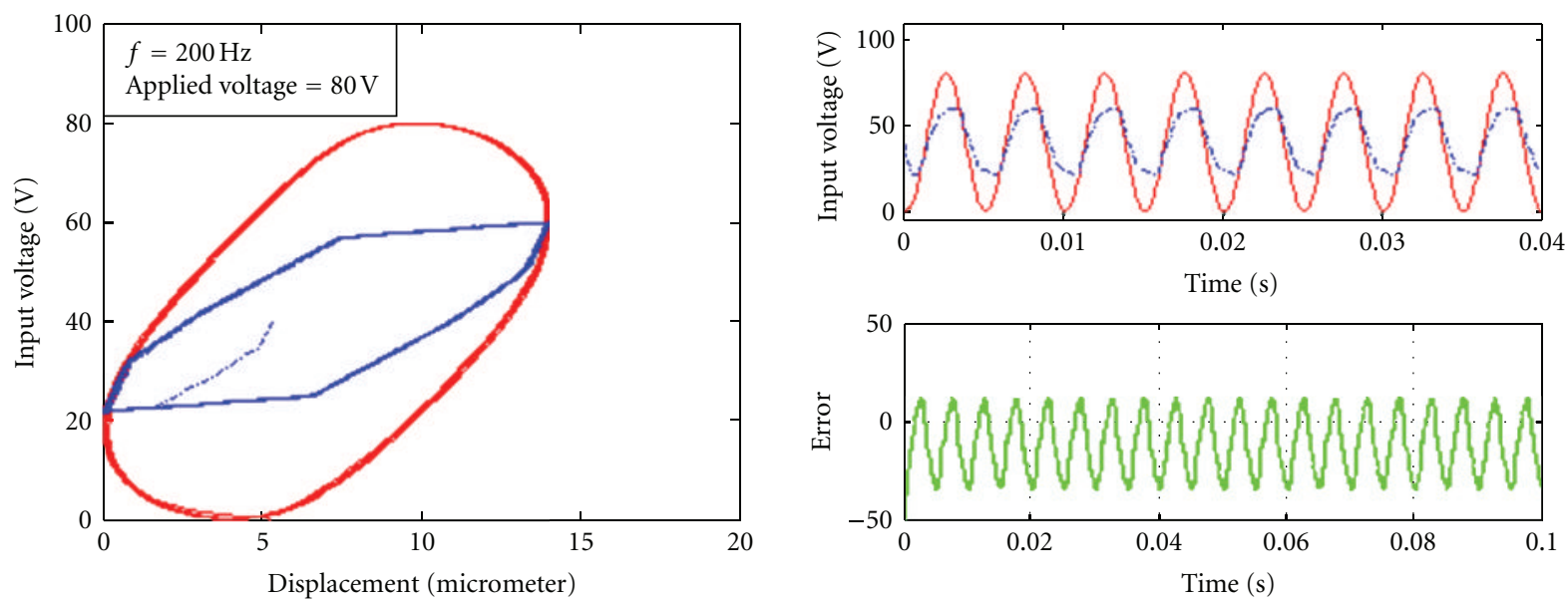

- Measured output

- Measured output

-.- Model output

(f)

FIGURE 7: The results of modeling with the classical PI for load-free piezoelectric actuator for different input voltage and frequency: (a) 40 V; $10 \mathrm{~Hz}$, (b) $80 \mathrm{~V} ; 10 \mathrm{~Hz}$, (c) $40 \mathrm{~V} ; 25 \mathrm{~Hz}$, (d) $80 \mathrm{~V} ; 25 \mathrm{~Hz}$, (e) $40 \mathrm{~V} ; 200 \mathrm{~Hz}$, (f) $80 \mathrm{~V} ; 200 \mathrm{~Hz}$. 

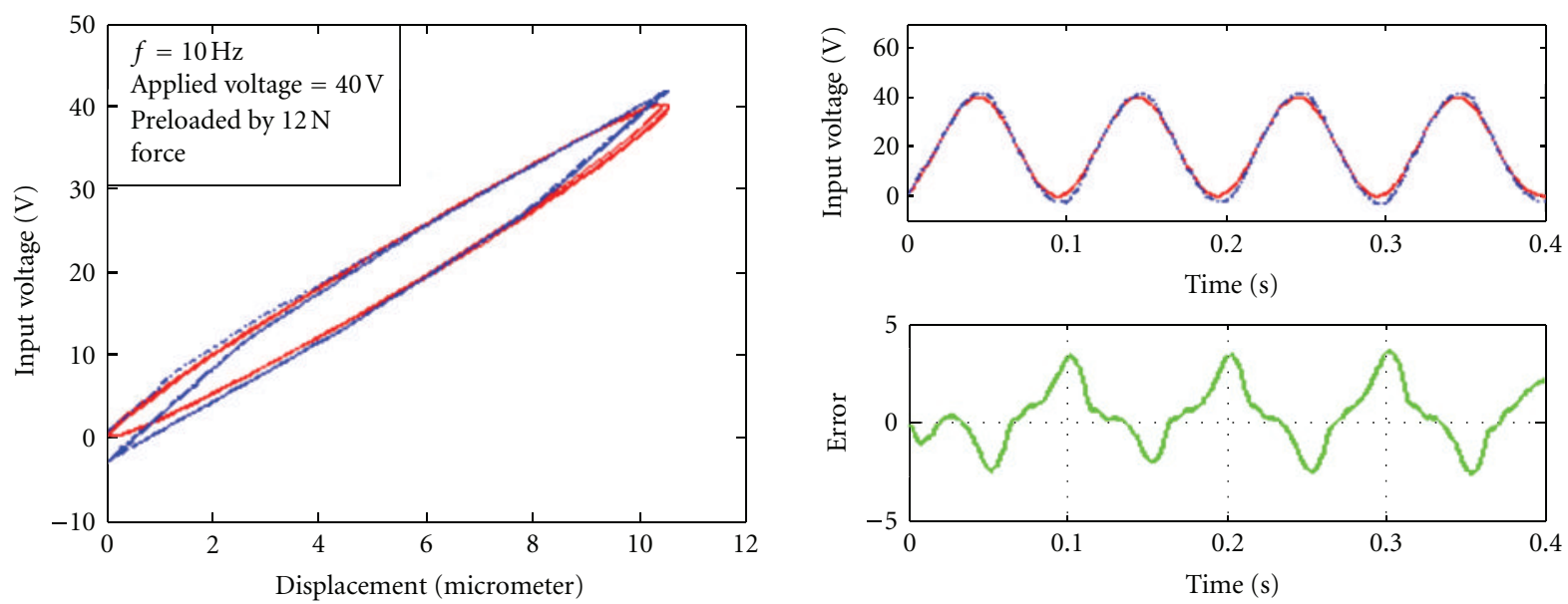

(a)
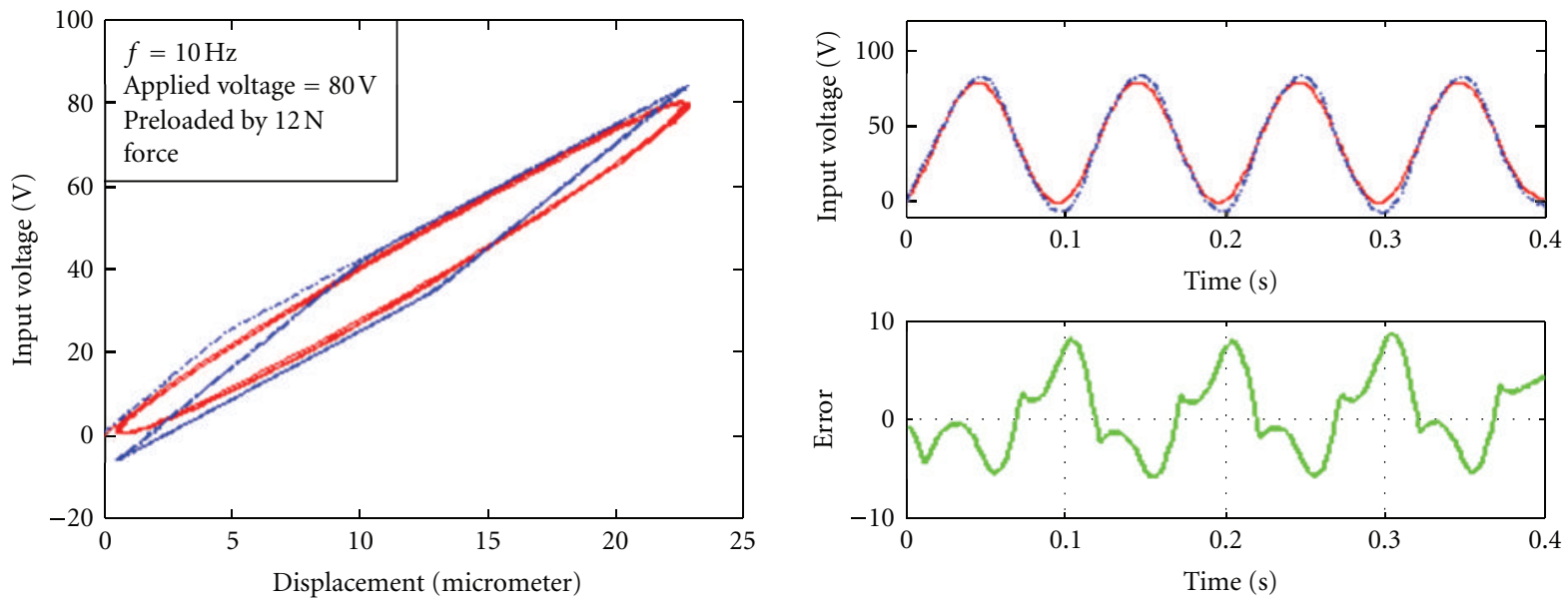

(b)
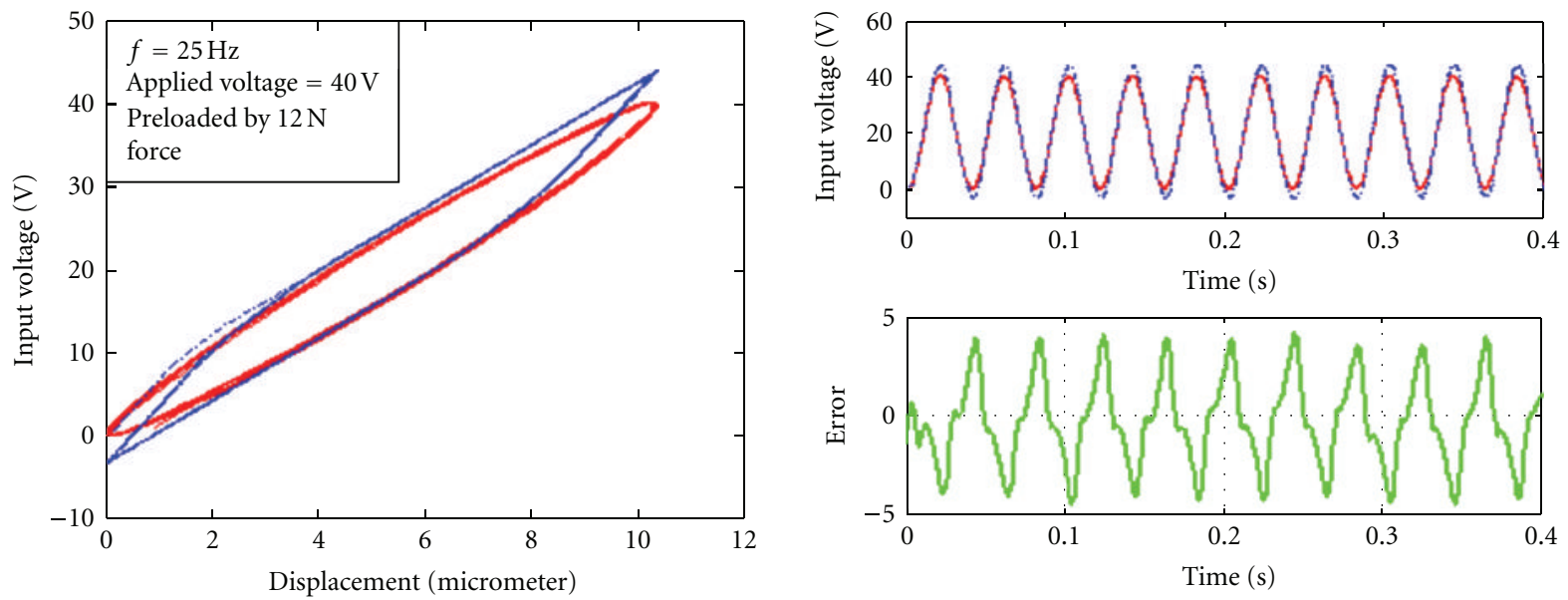

- Measured output

. ..- Model output

(c)

Figure 8: Continued. 

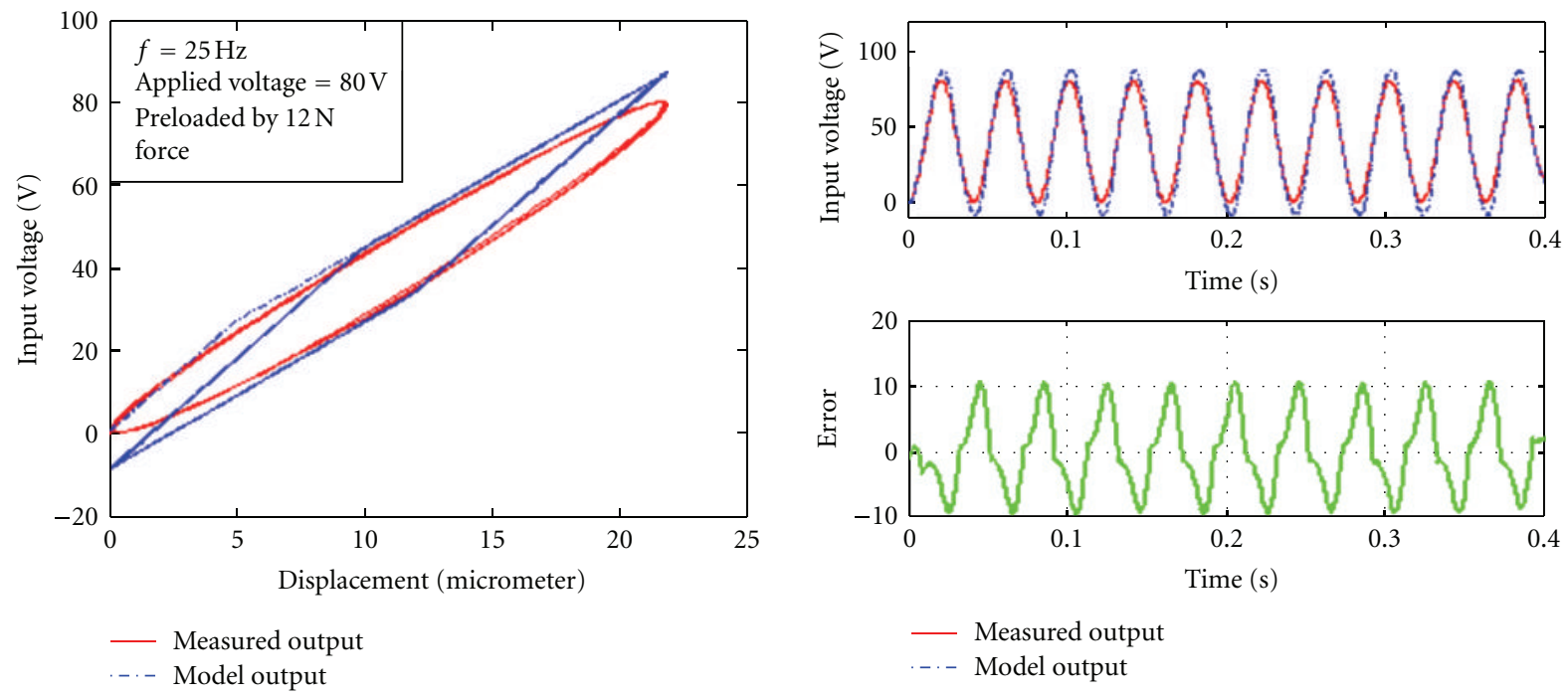

(d)

FIgURE 8: The results of modeling with the classical PI for preloaded piezoelectric actuator under $12 \mathrm{~N}$ force, for different input voltage and frequency: (a) $40 \mathrm{~V}$ and $10 \mathrm{~Hz}$, (b) $80 \mathrm{~V}$ and $10 \mathrm{~Hz}$, (c) $40 \mathrm{~V}$ and $25 \mathrm{~Hz}$, and (d) $80 \mathrm{~V}$ and $25 \mathrm{~Hz}$.

results also show that the maximum width of hysteresis curve is expanded when the magnitude of the applied voltage is increased.

Figure 5 shows the hysteresis obtained from the experiments to characterize the properties of the piezoelectric actuator under preloading condition at three different preloading forces applied to the piezoceramic. From the experiment results using two input signals, the most important thing that can be concluded is that the expansion of the hysteresis curve corresponds to the preloading force. For the case with an input voltage of $40 \mathrm{~V}$ and frequency of $200 \mathrm{~Hz}$, the width of the hysteresis is expanded 1.06 times from preloading force of $4 \mathrm{~N}$ to preloading force of $12 \mathrm{~N}$. In the case with the input voltage of $80 \mathrm{~V}$ and frequency of $200 \mathrm{~Hz}$, this value has shifted up to 1.11 times under preloading force of $4 \mathrm{~N}$ in comparison with the preloading force of $12 \mathrm{~N}$. This characterization shows that the intensity of hysteresis is increasing with the preloading forces, and consequently the quantity of maximum displacement of the actuator is also decreasing with increasing preloading force.

The second finding of this experiment is regarding the relationship between the maximum stroke of the actuator and maximum input voltage applied to the actuator. For the case of $40 \mathrm{~V}$ input, the maximum stroke of $10.12 \mu \mathrm{m}$ is obtained at frequency of $10 \mathrm{~Hz}$, and maximum stroke of $9.454 \mu \mathrm{m}$ is obtained at frequency of $200 \mathrm{~Hz}$. For the case of $80 \mathrm{~V}$ input, different values are acquired; meanwhile, the difference between the lowest and the highest stroke of the actuator at frequency of $10 \mathrm{~Hz}$ and $200 \mathrm{~Hz}$ is larger than that of the case in the $40 \mathrm{~V}$ input. These values are subsequently $21.57 \mu \mathrm{m}$ and $13.81 \mu \mathrm{m}$ for frequencies of $10 \mathrm{~Hz}$ and $200 \mathrm{~Hz}$. The same phenomenon is also observed under the preloading condition.

The third finding observed from this experiment is regarding a tight relationship between amplitude and fre- quency in one hand and asymmetrical hysteresis shape and high slope of the hysteresis curve in the other hand. As illustrated in Figures 5 and 6, if the amplitude of the input voltage is increased, the asymmetric hysteresis curve will be formed at low frequencies as compared to application of the low amplitude input, and the slope of the hysteresis curve is also increasing. In the case of the input voltage with magnitude of $80 \mathrm{~V}$, the asymmetric hysteresis curve is obtained at frequency of $125 \mathrm{~Hz}$, while the asymmetric hysteresis is observed at $250 \mathrm{~Hz}$ for the lower input amplitude of $40 \mathrm{~V}$.

\section{Modeling Results}

In order to capture the symmetrical hysteresis shapes, which are recorded up to $200 \mathrm{~Hz}$ with low-amplitude and highamplitude voltages, a stop operator was utilized. As described in Section 2, a stop operator plays a role as the inverse of the play operator. The implementation of the stop operator instead of the play operator enables us to use the PI model in a feed-forward loop for positioning control purposes so that it can generate the required control input upon a desired displacement commanded to the control system.

The classical PI model was implemented to characterize the hysteresis in the piezoelectric actuator by utilizing four classical stop operators, in the cases, where the symmetric hysteresis curve takes place. This modeling approach is parameterized by four threshold values of $r$ and multipliers of $w$, where $r$ adjusts the width and height of the hysteresis and $w$ adjusts the slope of the hysteresis curve correspondingly. These parameters are optimized upon the minimization of the following cost function:

$$
J=\sum_{i=1}^{n}\left(y_{S \cdot O}-y_{m}\right)^{2},
$$



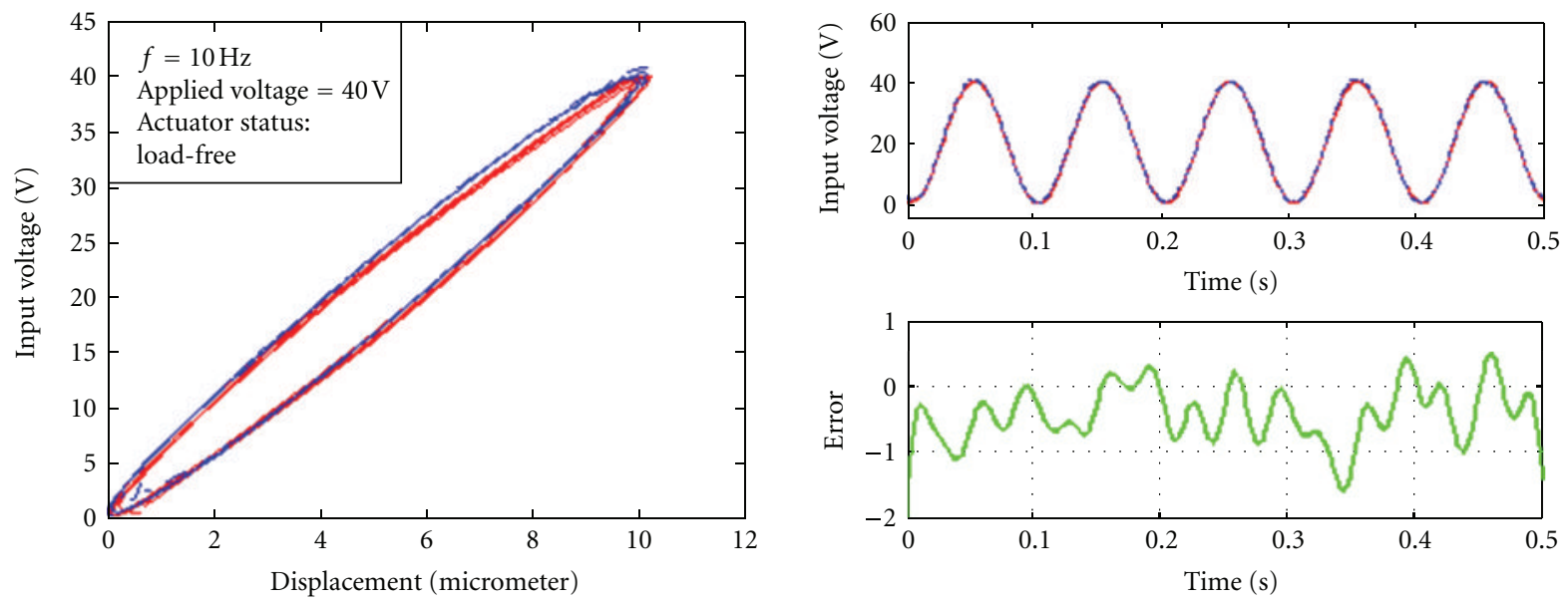

(a)
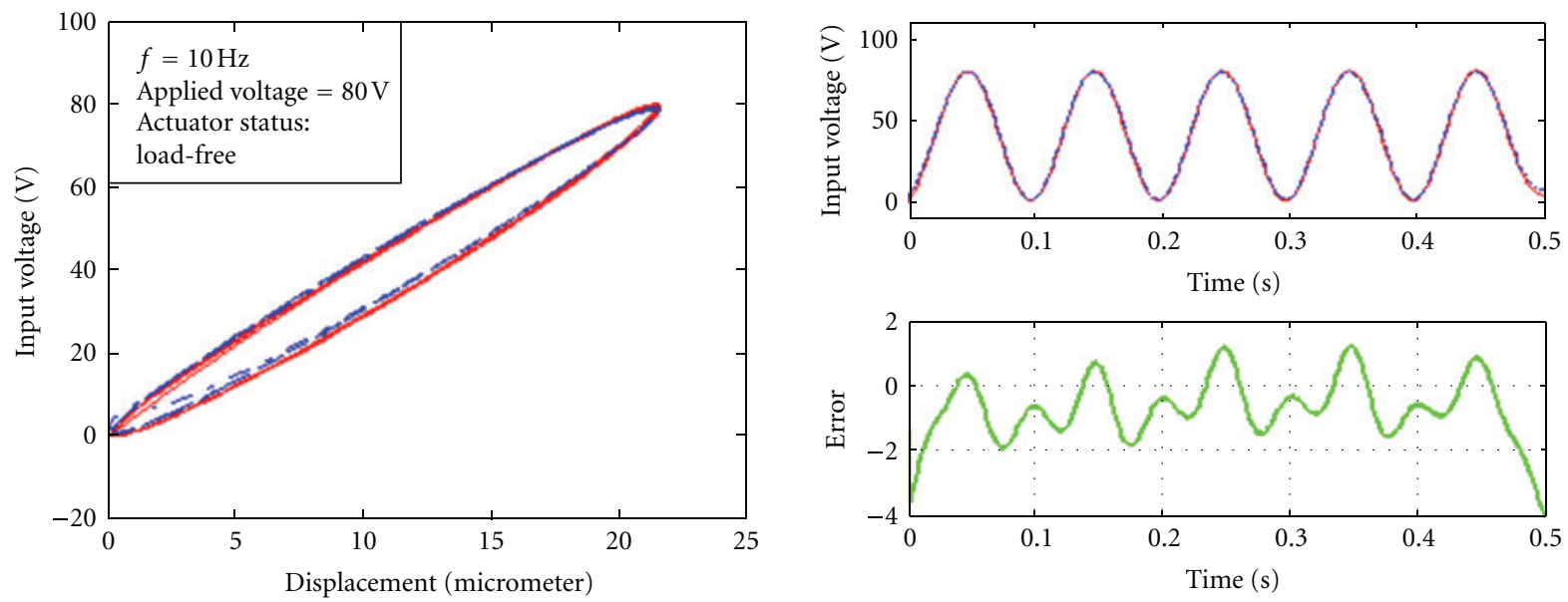

(b)
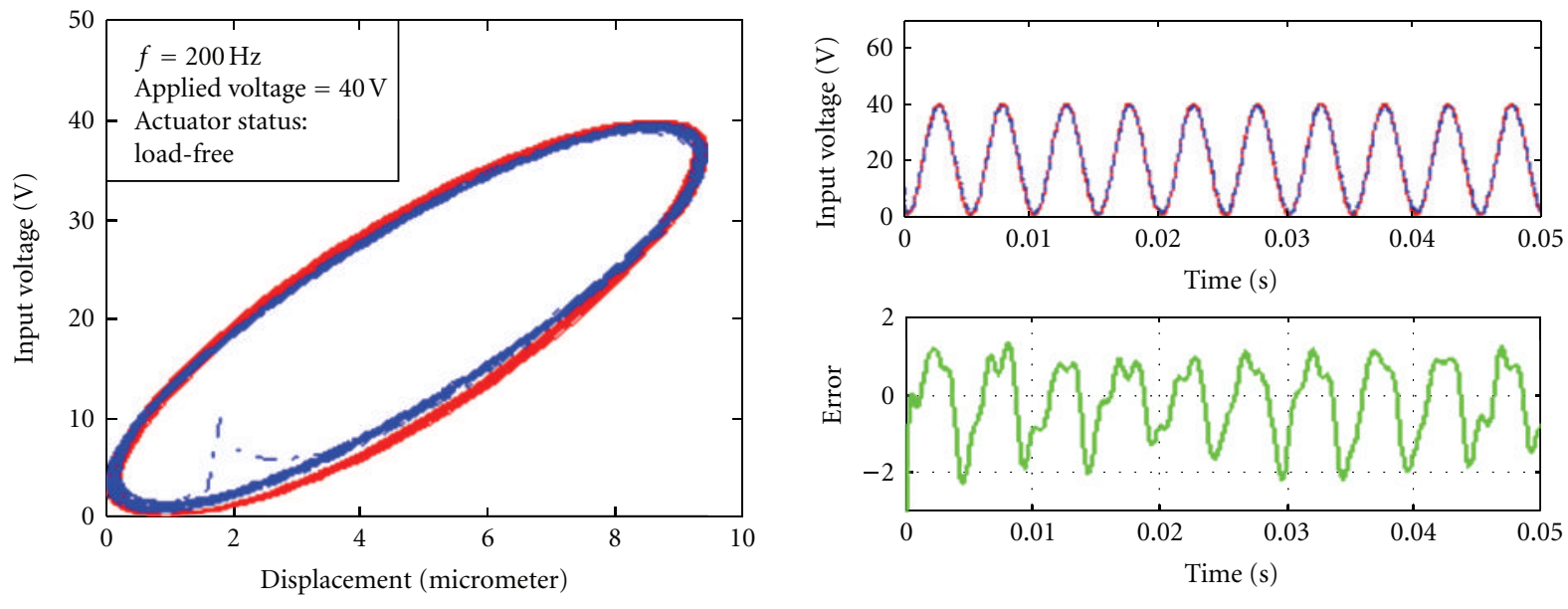

- Measured output

— Measured output

... Model output

(c)

Figure 9: Continued. 

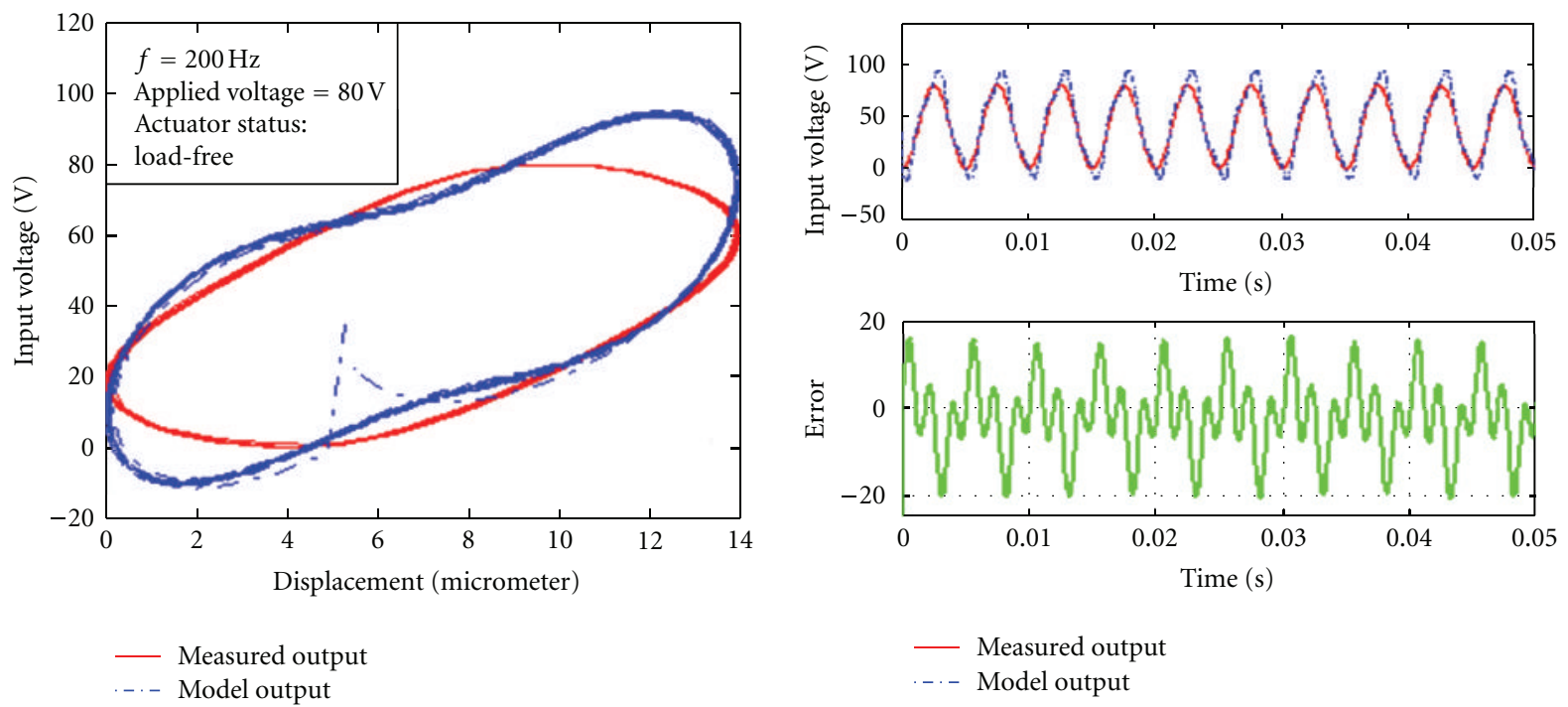

- Measured output

(d)

FIgURE 9: The results of modeling with Inertial-dependent PI for load-free actuator with different input voltage and frequency: (a) $40 \mathrm{~V}$ and $10 \mathrm{~Hz}$, (b) $80 \mathrm{~V}$ and $10 \mathrm{~Hz}$, (c) $40 \mathrm{~V}$ and $200 \mathrm{~Hz}$, and (d) $80 \mathrm{~V}$ and $200 \mathrm{~Hz}$.

where $y_{S . O}$ is the output of the stop operator in PI model and $y_{m}$ is the actual output which was measured from the experiment and $n$ is the number of samples. The error minimization problem was solved using the MATLAB optimization toolbox.

As can be seen in Figures 7 and 8 the classical PI model is not capturing the hysteresis pattern satisfactorily, in particular at high frequencies for both cases of the unloaded and preloaded actuator.

In order to overcome the problem, as discussed in the previous section, the inertial-dependent model is introduced, where two important dynamic terms of inertial and damping effects, which are stated by $m_{e q} \ddot{X}$ and $c_{e q} \dot{X}$, are taken into account. In the sense of frequency response, these two terms are expressed by $m_{e q} \omega^{2} X$ and $c_{e q} \omega X$. Intuitively, the physical aspect of the actuator will also manifest itself in the dynamics of the system. The classical PI model cannot be used solely in characterizing the hysteresis properties of the material. In Figures 7(a) to 7(f), it is shown that the classical PI model cannot capture the hysteresis pattern especially at the turning points, where the major lag occurs between the applied electrical field and actuator displacement. At these points, the PI model generates sharp turning points due to the absence of inertial and damping effects. In order to tackle this discrepancy, inertial-dependent model is implemented to capture the turning points as well as other points of the hysteresis curve with considerable reduction of error as illustrated in Figures 9(a)-9(d). In these figures, the results of simulation from the inertial-dependent PI model are displayed, where the amount of error between the measured output and the output of the inertial-dependent PI is significantly reduced compared to that from the classical PI model.

One of the interesting points appears from the characterization of the hysteresis at frequency of $200 \mathrm{~Hz}$ with high-amplitude voltage, where the hysteresis curve starts to skew resulting in an asymmetrical hysteresis. The error in this case seems to be larger compared to the cases at lower frequencies (see Figure 9(d)), which implies that the asymmetric hysteresis is still not incorporated in this model, despite the considerable amount of error that has been reduced in the symmetric hysteresis cases.

Figure 10 shows the identification results using the inertial-dependent PI model for the piezoelectric actuator under preloading forces of $4 \mathrm{~N}, 8 \mathrm{~N}$, and $12 \mathrm{~N}$. The first three panels (Figures 10(a)-10(c)) represent the preloading cases for the first applied voltage signal $(40 \mathrm{~V})$, where the last three panels are for the case of the second voltage signal $(80 \mathrm{~V})$. It can be concluded that this model is also applicable to characterize the piezoelectric actuator under preloading condition with acceptable amount of error by using the inertial-dependent PI model with the consideration of the preloading force, $F_{P \cdot L}=F_{\text {ext }}+K_{\text {eq, ext }} \cdot x$.

The result shows that the introduction of the inertial and damping effect to the classical PI model improves the performance of the model in wide range of operation. As can be seen in Figures 7 and 8, the error between the measured output (voltage) and the actual output is increased from lower frequencies to higher frequencies in the classical PI model. Also, the quantity of the error for high-amplitude voltage is larger than the error for the low-amplitude voltage case. In the inertial-dependent model, not only the amount of error remains low at different amplitudes, but this amount also remains low at different frequency values. As a result, it can be realized that the classical PI model is not capable of characterization of the hysteresis at wide range of frequency solely.

On the other hand, from the simulation at different frequencies with different amplitudes in both preloading and 

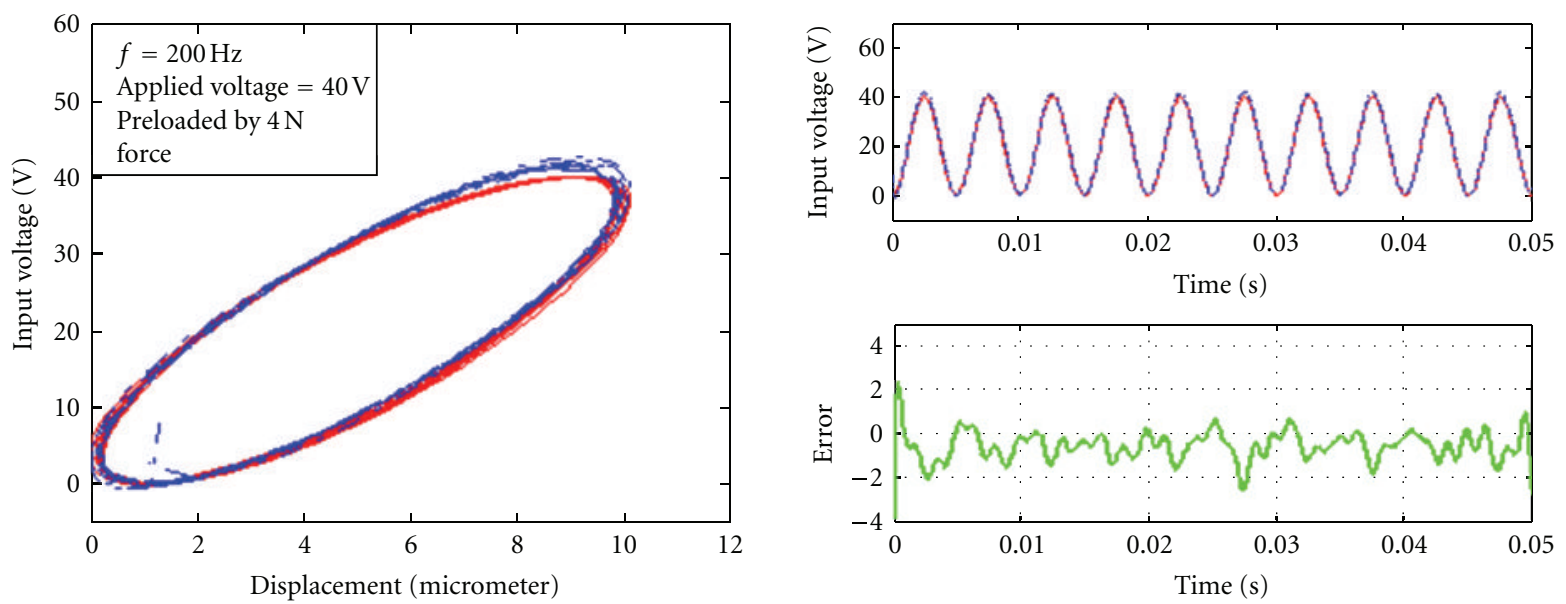

(a)
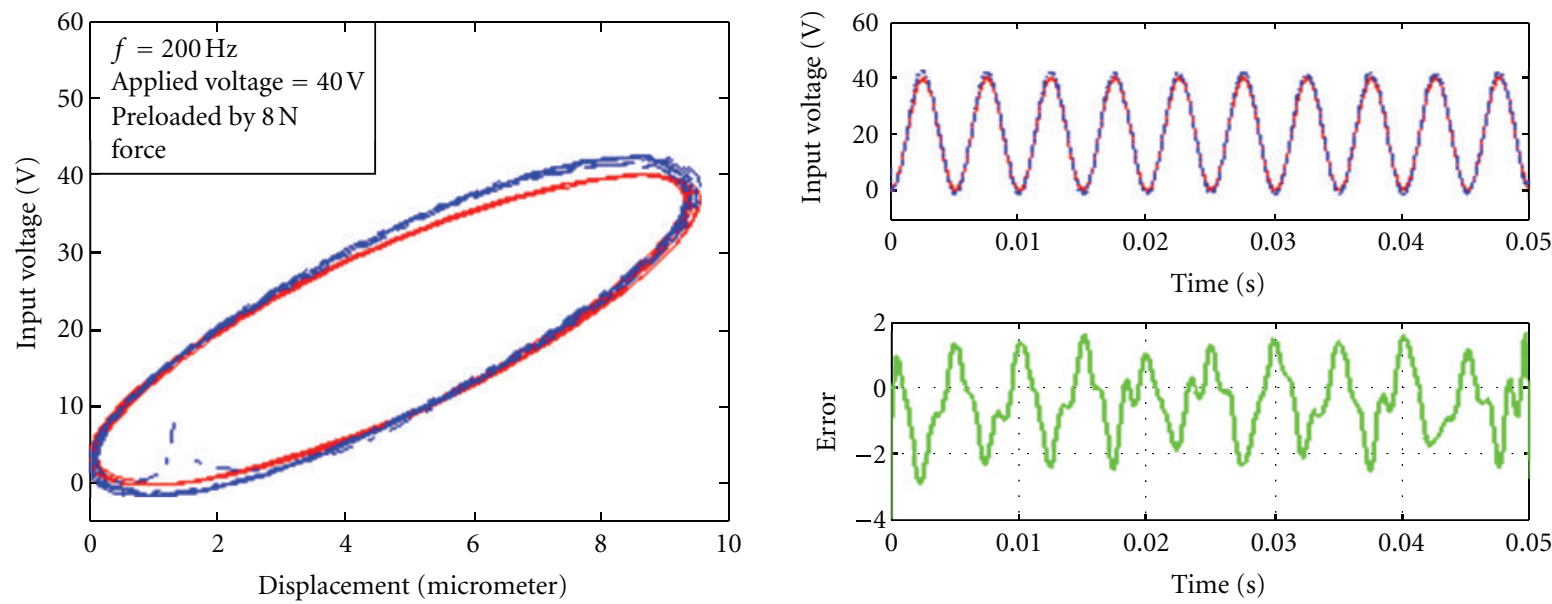

(b)
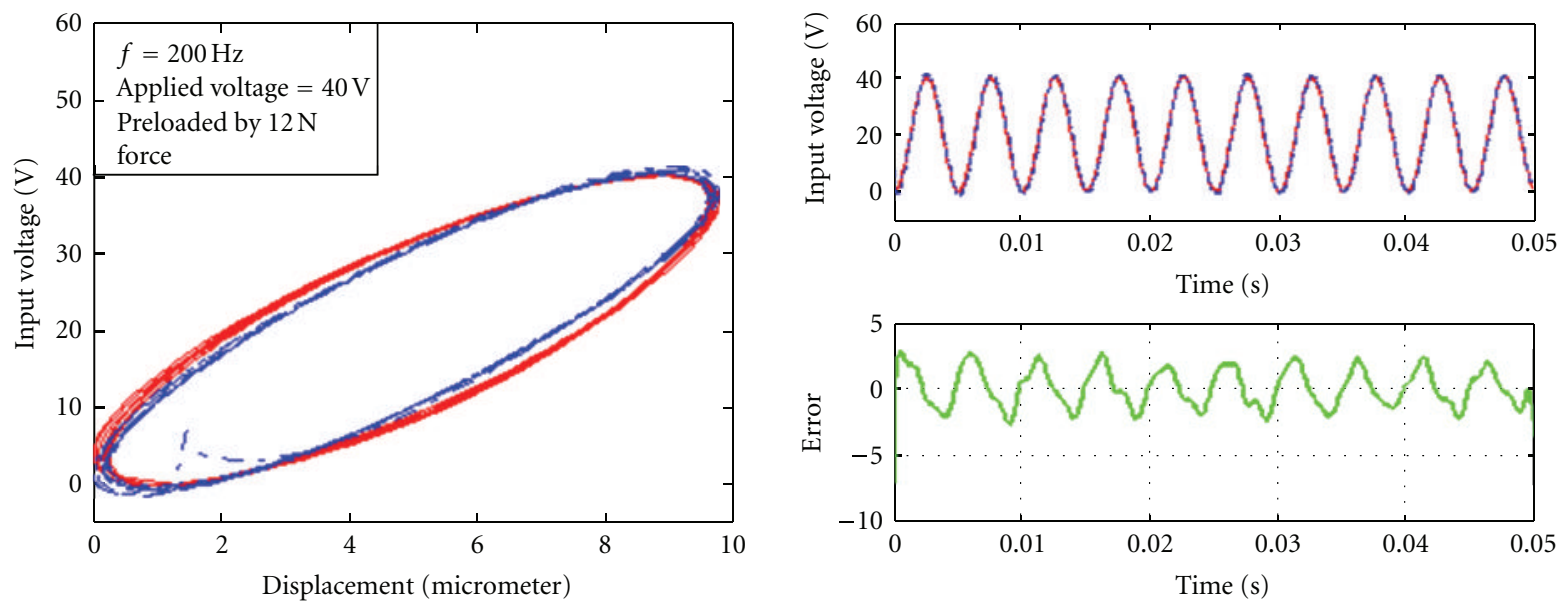

- Measured output

. -. Model output

- Measured output

-.. Model output

(c)

Figure 10: Continued. 

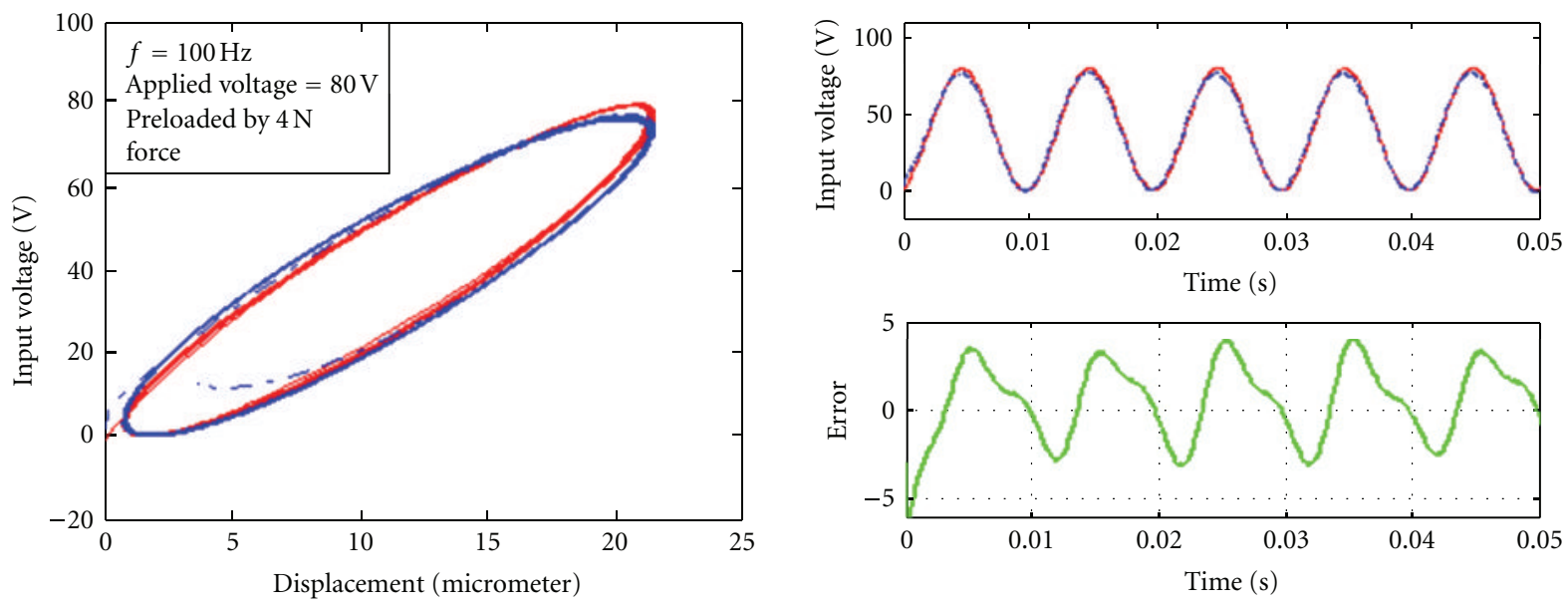

(d)
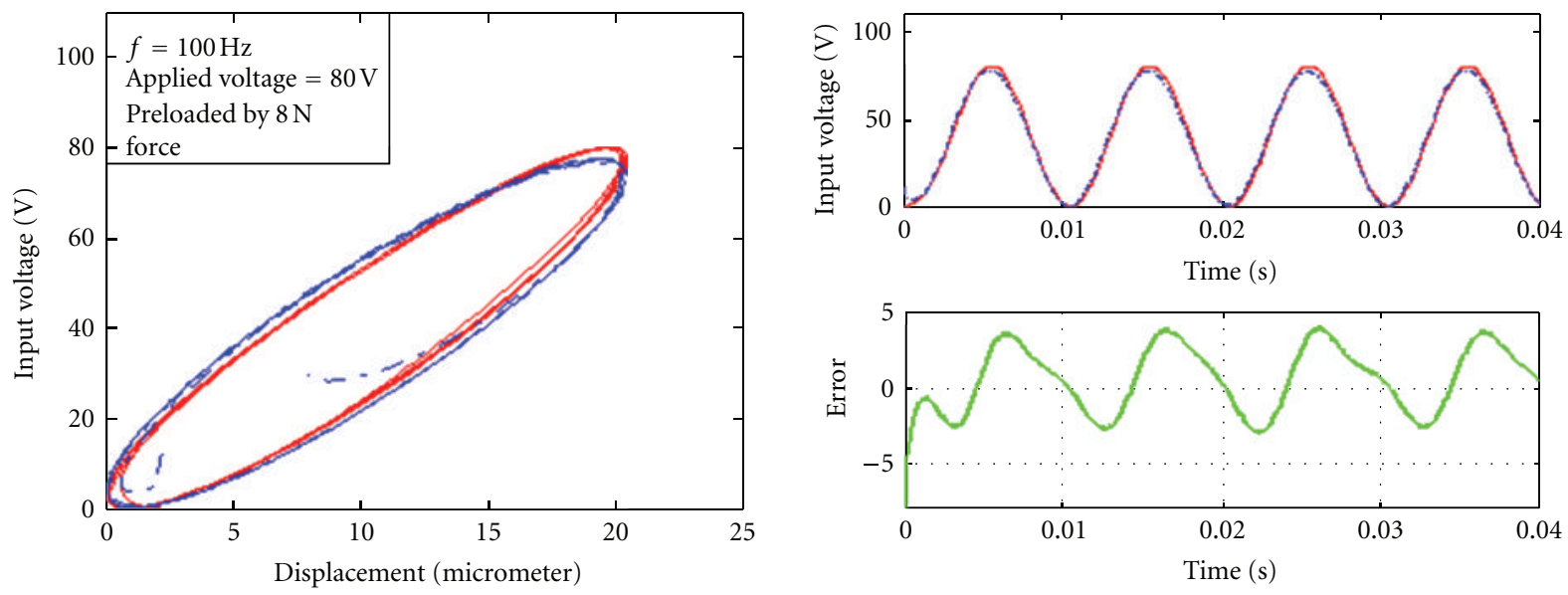

(e)
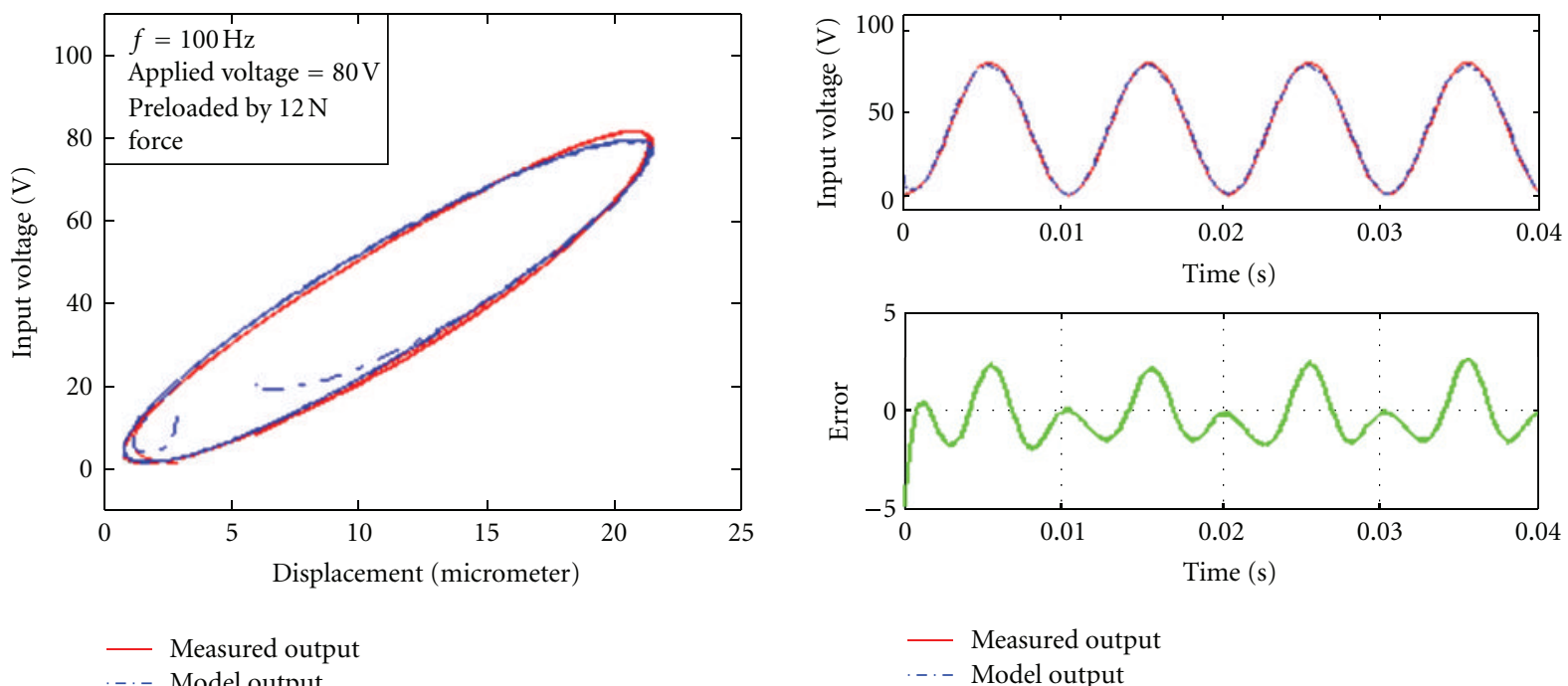

(f)

FigURE 10: The results of modeling with the inertial-dependent PI with different input voltage, frequency, and preload: (a) $40 \mathrm{~V} ; 200 \mathrm{~Hz} ; 4 \mathrm{~N}$, (b) $40 \mathrm{~V} ; 200 \mathrm{~Hz} ; 8 \mathrm{~N}$, (c) $40 \mathrm{~V} ; 200 ; 12 \mathrm{~N}$, (d) $80 \mathrm{~V} ; 100 \mathrm{~Hz} ; 4 \mathrm{~N}$, (e) $80 \mathrm{~V} ; 100 \mathrm{~Hz} ; 8 \mathrm{~N}$, and (f) $80 \mathrm{~V} ; 100 \mathrm{~Hz} ; 12 \mathrm{~N}$. 


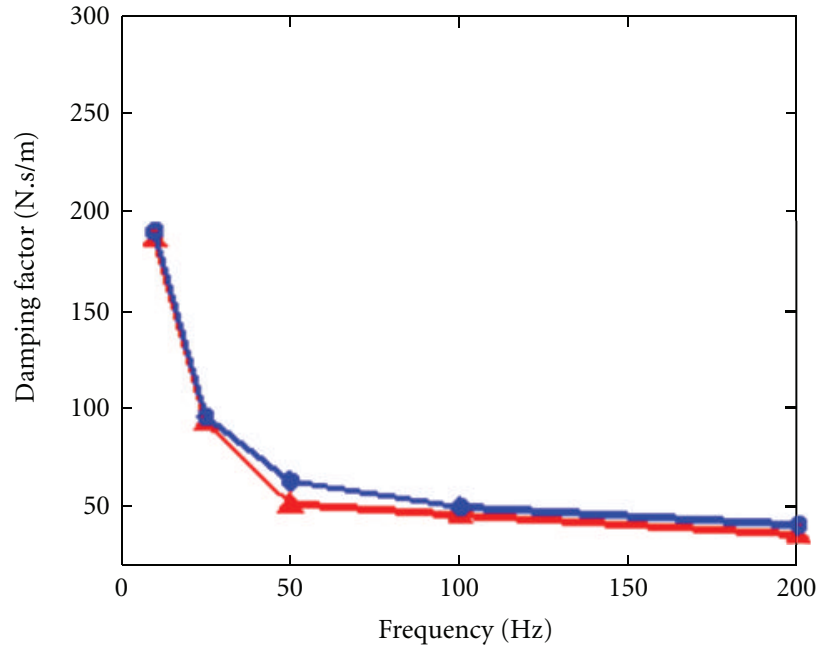

Damping factor variations of piezoelectric

- actuator under load-free condition for $40 \mathrm{~V}$ input

Damping factor variations of piezoelectric

- - actuator under load-free condition for $80 \mathrm{~V}$ input

(a)

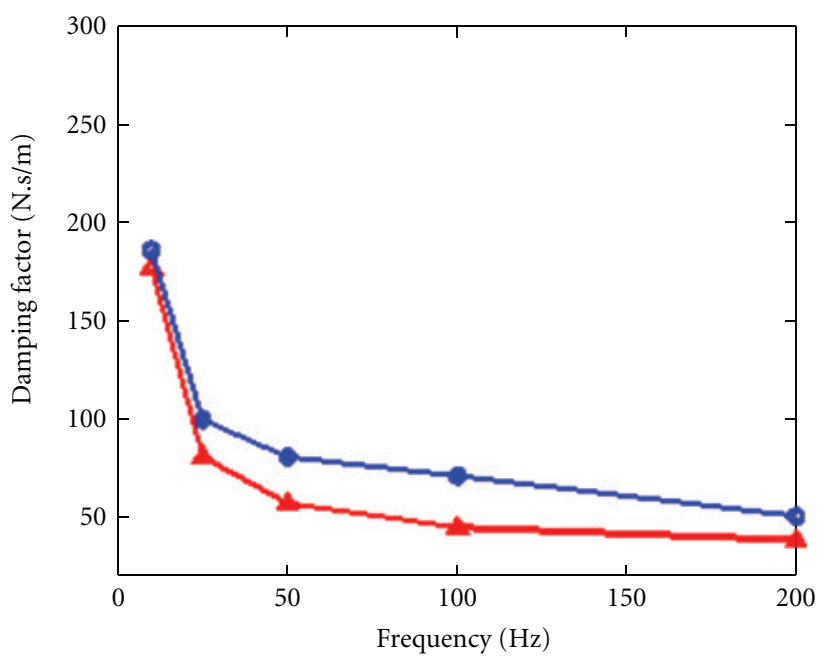

Damping factor variations of piezoelectric

- actuator under preloading force of $8 \mathrm{~N}$ and $40 \mathrm{~V}$ input

Damping factor variations of piezoelectric

- actuator under preloading force of $8 \mathrm{~N}$ and $80 \mathrm{~V}$ input

(c)

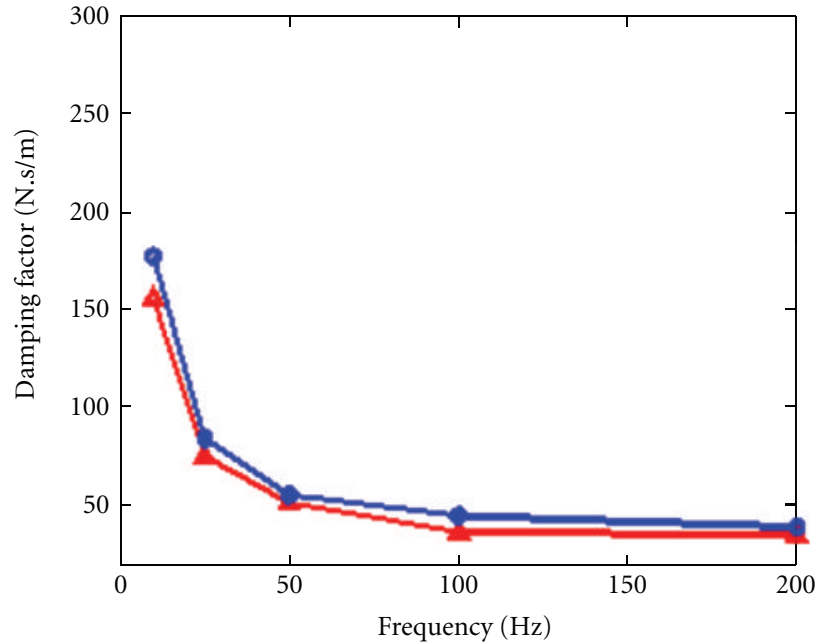

Damping factor variations of piezoelectric

- actuator under preloading force of $4 \mathrm{~N}$ and $40 \mathrm{~V}$ input

Damping factor variations of piezoelectric

- actuator under preloading force of $4 \mathrm{~N}$ and $80 \mathrm{~V}$ input

(b)

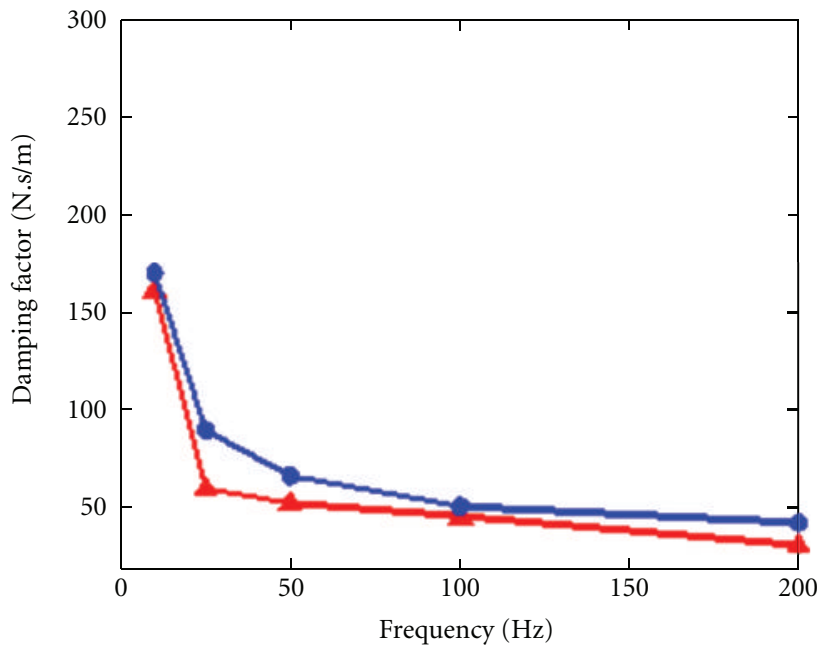

Damping factor variations of piezoelectric

$\triangle$ actuator under preloading force of $12 \mathrm{~N}$ and $40 \mathrm{~V}$ input

Damping factor variations of piezoelectric

$\rightarrow-$ actuator under preloading force of $12 \mathrm{~N}$ and $80 \mathrm{~V}$ input

(d)

Figure 11: Damping factor variations at different frequencies with different amplitudes ( $\mathbf{\Lambda}$, low-amplitude voltage, $40 \mathrm{~V}$; $\bullet$, high-amplitude voltage, $80 \mathrm{~V})$.

load-free circumstances, the parameter of damping effect is varying as illustrated in Figure 11. As the amplitude goes to higher values for both unloading and preloading conditions, the values of the damping factor shift to the higher values correspondingly, while the variation of the damping factor to the frequency is exponentially decreasing. On the other hand, in each set of the input voltage imposed to the actuator, the damping factor decreases with increasing the frequency value. This finding could be considered to be a guideline to develop an integrated rate and inertial-dependent model of hysteresis based on the variation of the damping factor versus frequency. 


\section{Conclusion}

In this study, the performance of the classical PI model was evaluated using sets of data which incorporate two different magnitudes of the input voltage and varying frequency from $10 \mathrm{~Hz}$ to $200 \mathrm{~Hz}$ for different preloading conditions. It is shown that the classical Prandtl-Ishlinskii model is unable to characterize the hysteresis in piezoelectric actuators at wide range of frequency and amplitude.

In order to tackle this problem, as the physical aspect of the piezoelectric actuator will manifest itself in the dynamic behavior, the inertial-dependent PI model is proposed to capture the hysteresis at different input amplitudes and frequencies. The proposed model exhibits better performance compared to that of the classical one as implied by the modeling error for wide range of applications. However, moving toward high-frequency applications, the performance of the proposed model is degrading. Incorporating the rate-dependent parameters, for example, as presented by Al-Janaideh et al. [8], to the inertial-dependent model is expected to improve the performance.

\section{References}

[1] Q. Wang, C. Y. Su, and S. S. Ge, "A direct method for robust adaptive nonlinear control with unknown hysteresis," in Proceedings of the 44th IEEE Conference on Decision and Control, \& the European Control Conference (CDC-ECC '05), vol. 1-8, pp. 3578-3583, December 2005.

[2] M. Al Janaideh, C. Y. Su, and S. Rakehja, "Modeling hysteresis of smart actautors," in Proceedings of the 5th International Symposium on Mechatronics and Its Applications (ISMA '08), Amman, Jordan, May 2008.

[3] P. Krejci and K. Kuhnen, "Inverse control of systems with hysteresis and creep," IEE Proceedings-Control Theory and Applications, vol. 148, no. 3, pp. 185-192, 2001.

[4] M. Al Janaideh, Y. Feng, S. Rakheja, C. Y. Su, and C. A. Rabbath, "Hysteresis compensation for smart actuators using inverse generalized prandtl-ishlinskii model," in Proceedings of the American Control Conference (ACC '09), pp. 307-312, St. Louis, Mo, USA, June 2009.

[5] M. Al Janaideh, Y. Feng, S. Rakheja, Y. Tan, and C. Y. Su, "Generalized Prandtl-Ishlinskii hysteresis: modeling and robust control for smart actuators," in Proceedings of the 48th IEEE Conference on Decision and Control and 28th Chinese Control Conference, pp. 7279-7284, 2009.

[6] X. Chen, "High precision control for piezo-actuated positioners," in Proceedings of the IEEE International Conference on Mechatronics and Automation (ICMA '09), pp. 966-971, Changchun, China, August 2009.

[7] M. Al Janaideh, S. Rakheja, and C. Y. Su, "Characterization of rate dependent hysteresis of piezoceramic actuators," in Proceedings of theIEEE International Conference on Mechatronics and Automation (ICMA '07), vol. 5, pp. 550-555, Haerbin, China, August 2007.

[8] M. A. Janaideh, S. Rakheja, and C. Y. Su, "Experimental characterization and modeling of rate-dependent hysteresis of a piezoceramic actuator," Mechatronics, vol. 19, no. 5, pp. 656670, 2009.

[9] K. Kuhnen and H. Janocha, "Complex hysteresis modeling of a broad class of hysteretic nonlinearities," in Proceedings of the 8th International Conference on New Actuators, Bremen, Germany, June 2002.

[10] W. T. Ang, F. A. Garmon, P. K. Khosla, and C. N. Riviere, "Modeling rate-dependent hysteresis in piezoelectric actuators," in Proceedings of IEEE/RSJ International Conference on Intelligent Robots and Systems, pp. 1975-1980, Pittsburgh, Pa, USA, October 2003.

[11] U.-X. Tan, W. T. Latt, C. Y. Shee, C. N. Riviere, and W. T. Ang, "Feedforward controller of ill-conditioned hysteresis using singularity-free Prandtl-Ishlinskii model," IEEE/ASME Transactions on Mechatronics, vol. 14, no. 5, pp. 598-605, 2009.

[12] X. Wang, Y. Mao, X. Wang, and C. Su, "Adaptive variable structure control of hysteresis in GMM actuators based on Prandtl-Ishlinskii model," in Proceedings of the 33rd Annual Conference of the IEEE Industrial Electronics Society (IECON '07), vol. 1-3, pp. 721-726, Taipei, Taiwan, November 2007.

[13] M. Goldfarb and N. Celanovic, "Modeling piezoelectric stack actuators for control of micromanipulation," IEEE Control Systems Magazine, vol. 17, no. 3, pp. 69-79, 1997.

[14] M. Quant, H. Elizalde, A. Flores, R. Ramírez, P. Orta, and G. Song, "A comprehensive model for piezoceramic actuators: modelling, validation and application," Smart Materials and Structures, vol. 18, no. 12, 2009.

[15] T. J. Yeh, S. W. Lu, and T. Y. Wu, "Modeling and identification of hysteresis in piezoelectric actuators," Journal of Dynamic Systems, Measurement and Control-Transactions of the ASME, vol. 128, no. 2, pp. 189-196, 2006.

[16] J. L. Ha, Y. S. Kung, R. F. Fung, and S. C. Hsien, "A comparison of fitness functions for the identification of a piezoelectric hysteretic actuator based on the real-coded genetic algorithm," Sensors and Actuators A, vol. 132, no. 2, pp. 643-650, 2006.

[17] J. L. Ha, R. F. Fung, and C. S. Yang, "Hysteresis identification and dynamic responses of the impact drive mechanism," Journal of Sound and Vibration, vol. 283, no. 3-5, pp. 943-956, 2005.

[18] A. Preumont, Vibration Control of Active Structures, An Introduction, Kluwer Academic Publishers, Dodrecht, The Netherlands, 2002. 

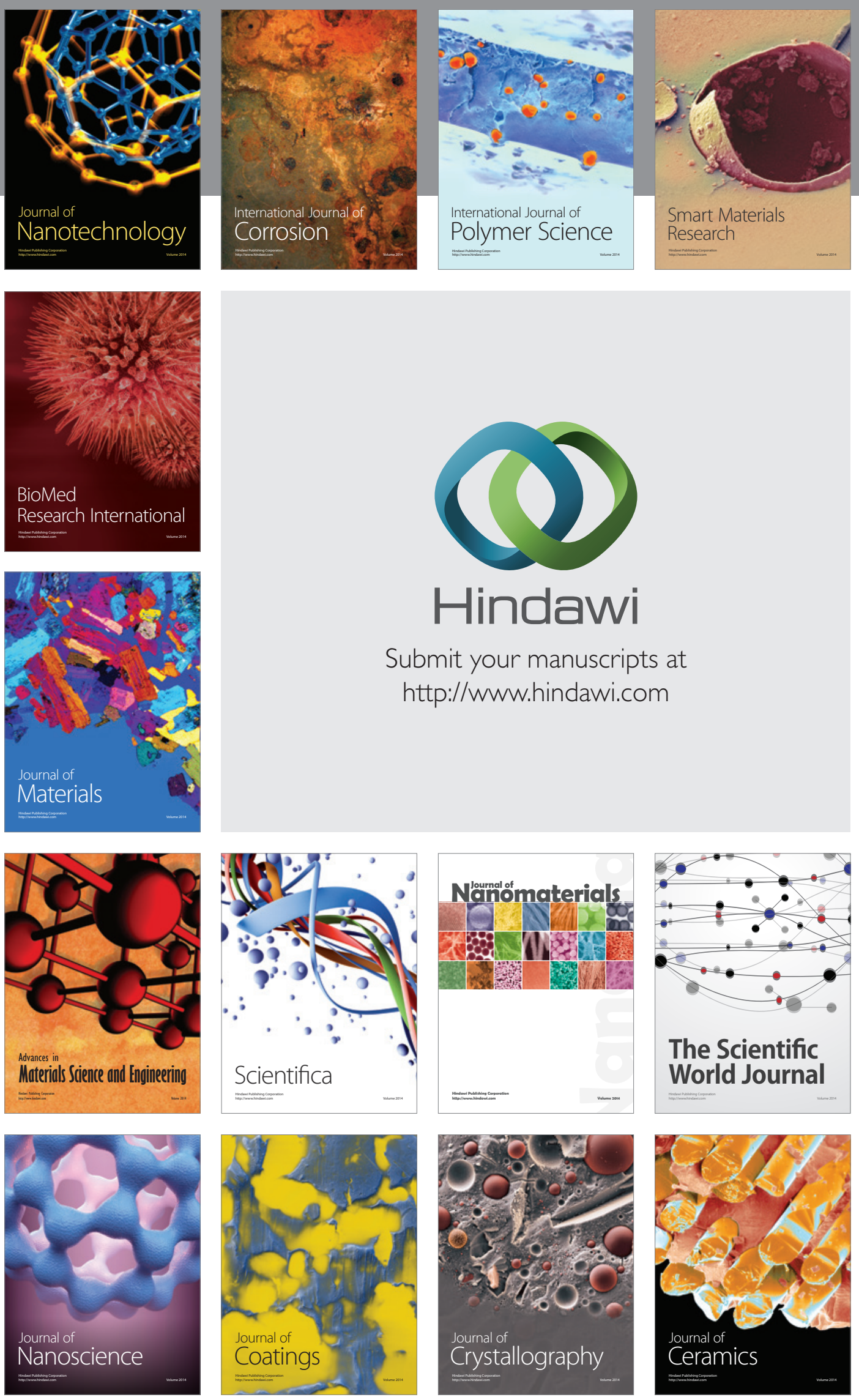

The Scientific World Journal

Submit your manuscripts at

http://www.hindawi.com

\section{World Journal}

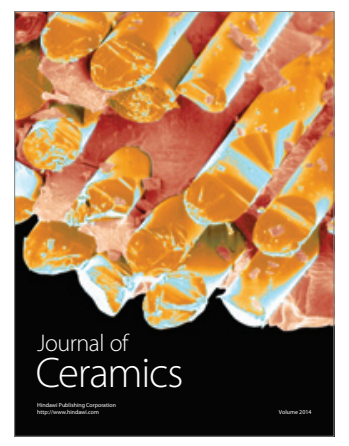

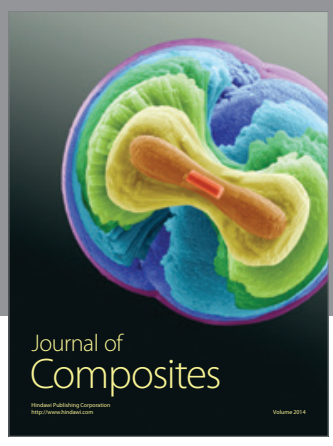
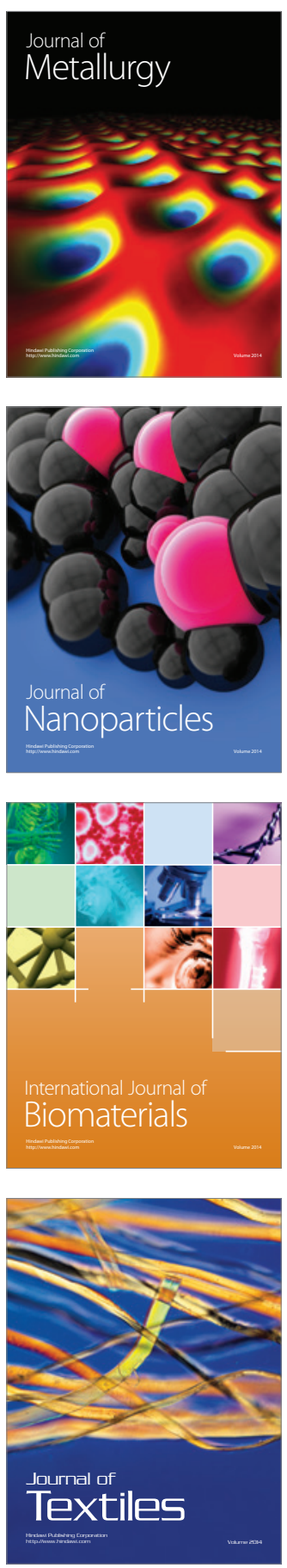